\title{
INTERNAL WAVE-DRIVEN MIXING: GOVERNING PROCESSES AND CONSEQUENCES FOR CLIMATE
}

\author{
Caitlin B. Whalen ${ }^{1 \dagger}$, Casimir de Lavergne ${ }^{2}$, Alberto C. Naveira Garabato ${ }^{3}$, Jody M. Klymak ${ }^{4}$, \\ Jennifer A. MacKinnon ${ }^{5}$, and Katy L. Sheen ${ }^{6}$. \\ 1 Applied Physics Laboratory, University of Washington, USA \\ ${ }^{2}$ LOCEAN Laboratory, Sorbonne Université-CNRS-IRD-MNHN, Paris F-75005, France, \\ 3 Ocean and Earth Science, National Oceanography Centre, University of Southampton, \\ Southampton, UK
}

${ }^{4}$ School of Earth and Ocean Sciences, and Department of Physics and Astronomy, University of Victoria, Victoria, Canada

${ }^{5}$ Scripps Institution of Oceanography, University of California San Diego, USA

${ }^{6}$ Centre for Geography and Environmental Science, University of Exeter Penryn Campus, Penryn, UK

†email: cbwhalen@uw.edu

Turbulent mixing from breaking oceanic internal waves drives a vertical transport of water, heat and other climatically important tracers in the ocean, thereby playing an important role in shaping the circulation and distributions of heat and carbon within the climate system. Linking internal wave-driven mixing to its impacts on climate poses a formidable challenge, since it requires understanding of the complex lifecycle of internal waves - including generation, propagation, and breaking into turbulence - and knowledge of the spatio-temporal variability of these processes in the diverse, rapidly evolving oceanic environment. This review traces the energy pathways from tides, winds and geostrophic currents to internal wave mixing while attempting to connect this mixing 
with the global climate system, with the aim of inspiring future work on internal wave-driven mixing across all scales.

- Tides, winds, and geographic currents can generate oceanic internal waves and as a result are major sources of energy for the internal wave field.

- Interactions between internal waves and topography, currents, or other internal waves can transfer energy to smaller spatiotemporal scales. However, how these processes combine to yield the observed internal wave environment is not well understood.

- Eventually, internal waves can become unstable, causing them to turbulently dissipate energy and mix water across density classes, thereby altering ocean dynamics.

- The location and timing of internal wave generation, energy transfer to smaller scales, and subsequent turbulent dissipation conspire to form the continually evolving global distribution of mixing from internal waves.

- The global climate is shaped by the magnitude and geography of internal wave mixing. Future work can provide an integrated understanding of internal wave mixing in an evolving climate system.

\section{Introduction}

Just like surface waves exist along the sharp density interface at the boundary between the ocean and atmosphere, internal waves are often supported by smooth vertical gradients in density far beneath the ocean's surface. Internal waves often become unstable and break, generating turbulence. A single patch of ocean turbulence from an unstable internal wave dissipates energy, alters the stratification by mixing water of different densities, and thereby plays an important dynamical role in the local environment. Close to the surface and the seafloor, instabilities that 
are unrelated to internal waves often dominate the production of turbulence $[1,2]$. However, away from surface and bottom boundaries, internal waves are the primary cause of turbulent mixing.

In aggregate, such small (centimeter to meter) scale mixing from internal waves is essential for sustaining the global overturning circulation $[3,4,5,6]$ and closing the global ocean energy budget $[7,8,9]$. Internal wave-driven mixing is also important for transporting tracers such as nutrients, greenhouse gases, and carbon $[10,11,12,13,14]$ around the planet, thus shaping the biological landscape of the global ocean [15]. Mixing from internal waves varies substantially in both space and time throughout the ocean. Its distribution is set by the diverse processes that generate internal waves (including tides, winds or larger-scale geostrophic ocean currents), alter their propagation, and facilitate their dissipation. The complexity of the internal wave lifecycle leading to turbulent mixing has inspired many avenues of inquiry.

Early work focused on understanding the local physics of internal waves [16, 17, 18, 19], and hypothesized that the mixing caused by these waves has global implications [20]. More recent efforts to study internal wave-driven mixing have advanced our understanding of the local physics, and linked internal wave processes inducing mixing that are disparate in space and time to a holistic view of the entire ocean system. Recent reviews have focused specific threads of areas of rapid development, including parameterization of internal wave-driven mixing in climate models [21], and reported on the current understanding of internal waves near the inertial frequency [22].

This review will adopt a wider perspective by targeting internal wave physical processes and how they contribute to setting the complex spatio-temporal structure of mixing in the ocean. After describing the physics of mixing due to breaking internal waves, the review will examine internal wave energy pathways, categorized according to the waves' energy source. Subsequently, the review will outline implications of internal wave-driven mixing for global ocean circulation and climate, emphasizing knowledge frontiers. 


\section{Physics of Mixing from Internal Waves}

Internal waves are ubiquitous in the stratified ocean interior. Flow along the uneven seafloor, perturbations at the base of the mixed layer, or fluctuating ocean currents can all generate internal waves (Figure 1). The signature of the generation mechanism is imprinted on the internal waves' spatial and temporal characteristics, leading to internal waves that have horizontal scales of order 0.1-100 kilometers and vertical scales that range from meters to scales comparable to the ocean depth. The structure and behaviour of internal waves is often modeled using orthogonal modes [G] [23]. Waves with vertical scales comparable to the ocean depth have small mode numbers and are called 'low-mode internal waves', whereas waves with smaller vertical scales have large mode numbers and are called 'high-mode internal waves' [23]. The high-mode internal waves can often occur in packets with vertical extents of hundreds of meters. The horizontal group velocity (that is, the velocity of energy propagation) is inversely proportional to mode number, such that low-mode wave energy travels faster than high-mode energy. The frequencies of internal waves are roughly bounded on the high end by the buoyancy frequency $[\mathrm{G}](N)$ and on the low side by the local Coriolis frequency [G] (that is, the inertial frequency, $f$ ). A single generation event generally produces a spectrum of waves with a range of spatial scales and frequencies.

Once the internal waves are generated, they propagate throughout the ocean, interacting with other waves, currents and topography in ways that lead to a transfer of energy across scales and a loss of coherence of the initial waves. Far from boundaries, wave-wave interactions are a major process that can transfer energy to smaller scales $[24,25,26]$. Wave-wave interactions involve a resonance or near-resonance between three or more internal waves, causing an exchange of energy between waves of different wavelengths and frequencies that can shift energy to waves on smaller spatiotemporal scales. A particularly efficient class of wave-wave interactions occurs when one or more of the high-mode internal waves have near-zero group velocity, allowing sustained growth due 
to energy transfer with a low-mode wave of approximately double their frequency, through a process known as parametric subharmonic instability [27, 28, 29]. Additionally, as internal waves propagate through variable background velocity and stratification, their length scales and group velocity may change. For example, substantial variability in the background field can induce a rapid decrease in the vertical scale of the wave, referred to as a critical layer [30, 31, 32]. Close to the seafloor, the dominant dynamics change, and the scattering of internal waves off rough topographic features or continental slopes is the most important class of processes that can turn larger-scale waves into smaller-scale ones.

Ultimately, internal waves cascade to small enough scales to trigger a mixture of shear and convective instabilities, turbulently dissipating wave energy through the internal wave equivalent of breaking [33]. For example, shear instabilities can extract kinetic energy from an internal wave, inducing turbulence (for example, Figure 2a-b). Alternatively, an internal wave can also generate turbulence through convective instability that occurs when denser water at the wave crest moves over lighter water [34], producing turbulence by extracting potential energy from the wave (for example, Figure 2c-d). The turbulence generated by internal waves in the open ocean is typically patchy and intermittent, exhibiting spatial scales of order 0.1-100 $\mathrm{m}$ and time scales of minutes to hours $[35,36]$. Where and when an internal wave dissipates energy depends strongly on the mode number of the wave, since the mode sets the vertical scale, group velocity, and susceptibility to wave-wave interactions $[37,38]$.

Breaking internal waves create turbulent kinetic energy, which is then either lost to viscous dissipation (at a rate $\epsilon$ ) $[\mathrm{G}]$ or to work against the ocean's density gradients (expressed as a buoyancy flux, $\left.J_{b}\right)$. The two are related by the flux coefficient $\Gamma=J_{b} / \epsilon[39,40]$. The buoyancy flux can be expressed as a down-gradient mixing of density at a rate given by a diapycnal diffusivity [G] $K$, so 
that $J_{b}=K N^{2}$, or

$$
K=\frac{\Gamma \epsilon}{N^{2}} .
$$

$K$ is the variable ultimately needed to model vertical mixing of oceanic tracers. Realistic representation of internal wave-driven mixing thus requires knowledge of the turbulent kinetic energy dissipation rate $\epsilon$ and of the flux coefficient $\Gamma$ [39]. In open-ocean internal wave environments, the flux coefficient is often close to 0.2 ; however a number of studies do indicate that $\Gamma$ can vary throughout the ocean [40].

There are two primary observational approaches to estimate the intensity of turbulence associated with internal waves: direct and indirect methods. Spectra of oceanic shear on centimeter scales measured with microstructure probes can be compared directly to theoretical turbulence spectra and used to calculate $\epsilon[41,42]$. Indirect methods use finescale measurements (on 1-10 m scales) that are analogously compared to internal wave spectra via the adoption of more assumptions, in order to provide the turbulent kinetic energy dissipation rate expected from an observed internal wave field $[43,44,45,46]$. Finescale measurements generally agree with microstructure measurements within a factor of $2-3[45,47,48]$ in the open-ocean thermocline when they are compared on equivalent time and length scales, which is considered a strong agreement, since dissipation rates vary over many orders of magnitude.

Next, we move from describing studies that target the physics of internal wave generation, propagation and breaking, to adopting a global perspective of the distribution and implications of internal wave-driven mixing.

\section{Global Internal Wave Energy Budget}

Knowledge of the global budget, including the pathways to and from the reservoir of internal wave energy, is key to fully characterize the impact of internal wave-driven mixing on global-scale 
ocean dynamics. The estimated energy budget of the open-ocean internal wave field is shown in Figure 3. Energy from three major sources contributes to internal waves: tides, surface winds associated with synoptic and mesoscale atmospheric disturbances, and geostrophic currents. Tidal flow moving water over uneven seafloor topography adds about $1 \mathrm{TW}$ of power to the internal wave field. A resonant response in the surface mixed layer to time-varying wind stress provides an estimated 0.3-1.4 TW of power, part of which fuels the internal wave field. Geostrophic currents flowing over small-scale topographic features, or losing balance, transfer energy to internal waves at estimated global rates of $0.15-0.75 \mathrm{TW}$ and $0.1-0.36 \mathrm{TW}$, respectively.

Once internal waves are generated, they enter the global reservoir of internal wave energy (Figure 3). This reservoir has a remarkably consistent distribution of wavenumbers and frequencies, presumably due to the prevalence of wave-wave interactions in distributing energy across length and time scales [49], which is modeled by the empirically derived Garrett-Munk spectrum [50, 51]. Observations reveal a more complex internal wave spectrum with considerable spatio-temporal variability $[52,53]$, including peaks at the tidal and inertial frequencies that are respectively attributed to generation by tides and time-variable winds, in addition to pronounced deviations near topography $[54]$ and in shallow water $[55,56]$. However, a complete understanding of what sets the energy level and shape of the internal wave spectrum, in particular the 'continuum' of the spectrum where there are no peaks, is still an area of active research.

Globally, the energy in the internal wave field is either lost through turbulent dissipation or transferred to the background ocean currents. Dissipation can occur close to the waves' generation sites, or up to thousands of kilometers away, making tracking energy through the system extremely challenging. Along the way, the internal waves are thought to exchange energy with the background current field, adding to the difficulty of closing the global internal wave energy budget and comprehensively mapping internal wave-driven mixing. 
Energy from the tides is a major contributor to the internal wave field energy budget [57], globally converting about $1 \mathrm{TW}$ of energy to open-ocean internal tides [58, 59]. Once internal waves at the tidal frequencies and their harmonics are generated, they travel through the ocean differently depending on their spatial scale; generally the high-mode waves dissipate in the near field (close to the generation site) and low-mode waves dissipate in the far field. The many pathways of internal tides from generation to dissipation yield a complex global geography of internal tide dissipation [60, 61, 62, 63], shown in Figure 4a.

6.1. Generation. Gravitational attraction of the moon and sun generates the ocean's batrotropic tides [G] [57], which uniformly span the full water column. Barotropic tidal currents dissipate about two thirds of their energy through friction and shear-driven mixing in shelf seas [64] and breaking coastal lee waves $[65,66]$. The remainder of barotropic tidal energy is dissipated through the generation of internal (baroclinic) tides [G], resulting from the periodic displacement of density surfaces by barotropic tidal currents pushing stratified fluid along a sloping seafloor $[19,57]$.

The character of the topography plays a primary role in setting the dominant modes of the internal tide: a tall and steep slope (e.g., a continental slope) tends to generate low-mode internal tides, whereas a flatter but corrugated bottom (e.g., an abyssal ridge flank) favours high modes [67, 68] (Figure 4b). A small number of sharp and steep topographic features contribute the majority of the power going into the first few modes $[69,70]$. Internal tides with the smallest scales, corresponding to modes $\gtrsim 50$, are mostly generated by "abyssal hills" [71, 72] that have typical widths of several kilometres and heights of a few hundred meters [73]. Generation by abyssal hills has been estimated to amount to about $0.1 \mathrm{TW}$ globally $[72,74]$, roughly $10 \%$ of the total conversion rate from barotropic to baroclinic tides. 
6.2. Near-field mixing. After internal tides are generated, a portion of the energy is dissipated in the near-field, close to the rough topographic features of origin $[75,76,71]$. In particular, direct nonlinear breaking and wave-wave interactions may both be responsible for the rapid energy transfer from high-mode internal tides to turbulence in close proximity to topography $[77,78,79]$ and in the upper water column $[60,78,74]$. Evidence for this near-field mixing due to internal waves include microstructure observations accumulated over the last 25 years showing that the turbulent dissipation rate is elevated multiple kilometers above or away from irregular topography, and that it often increases with greater proximity to that topography [75, 62]. Additionally, observations and model studies suggest that abyssal hill roughness underpins the bulk of the bottom-enhanced turbulence occurring over ridge flanks of the Pacific, Atlantic and Indian basins [78, 80, 74].

The geography of near-field mixing is challenging to model because the fraction of energy dissipated in the near field, and its vertical distribution, are a function of numerous factors including the local environment and the modal content of the internal tide. As a consequence of this complexity, in situ observations and theory indicate that the fraction of energy dissipated in the near field may range between 0.1 and $1[81,82,78,62,74,68]$. The power input to modes $\geq 4$ compares well with depth-integrated dissipation rates measured with microstructure probes, suggesting that modes $\geq 4$ dissipate mostly near their generation site [68]. These high modes represent an estimated 606 GW, or $49 \%$ of the total generation at seafloor depths exceeding $500 \mathrm{~m}$ [68]. Parameterizations of the full water column vertical distribution of near-field dissipation $[78,74]$ are often based on observations from the eastern Brazil Basin. Since the accuracy of these parameterizations on a global scale is largely unknown, observations across different regimes of high-mode internal tide generation [80, 83] will help to develop and improve confidence in parameterizations.

6.3. Propagation and far-field mixing. The distance that low-mode internal tides travel before dissipating their energy - often in the far field - depends on the mode number of the wave and the 
oceanic environment along the wave's path. First-mode internal tides propagating up to several thousands of kilometres can be detected using acoustic tomography and satellite altimetry [84, 85] and are dominated by distinct beams 100-300 km wide [70, 86] (Figure 4c). By contrast, identified mode-2 beams are more numerous but weaker, narrower and an order of magnitude shorter [87]. Mode 1 accounts for the bulk of internal tide horizontal energy transport [88], though modes 2-5 also contribute substantially [89, 90]; however, the exact fraction of energy transport in each mode depends on a number of environmental factors described below.

First, as internal waves propagate, variable bathymetry plays an important role in the transfer of low-mode energy to smaller scales, channeling the energy closer to the scale at which dissipation occurs $[91,92,63]$. When a large-scale wave bounces off short-scale seafloor irregularities, part of its energy is scattered into higher modes [93, 94], leading to bottom-intensified turbulence and dissipation. Larger-scale seamounts or ridges can also cause scattering to higher modes, as well as refraction of incident beams $[52,95,96]$. Beams that ultimately reach continental margins can reflect backward, dissipate or shoal, depending in part on the local topographic slope. Backward reflection dominates if the continental slope is significantly steeper than the wave $[97,98]$. If the topographic slope is approximately equal to the wave slope, energy is transferred to very high modes that break into small-scale turbulence along the slope [99, 100, 101]. Gentler continental slopes allow the internal tide to progress into shallow waters; however, as energy concentrates in the vertical, shear increases and direct breaking of the wave is frequent, particularly at the shelf break [102].

In addition to interactions with bathymetry, wave-wave interactions may also be significant in attenuating the mode-1 internal tides, and are likely dominant in draining energy from modes $\geq$ $2[28,103,38,63]$. The energy transfer is most efficient equatorward of the latitude at which the tidal frequency is twice the inertial frequency - that is, equatorward of $29^{\circ}$ for the dominant 
semidiurnal tidal constituent [29]. Resonant triads transfer energy to smaller vertical wavelengths, and ultimately to dissipation focused in the stratified upper ocean [104, 105, 106].

Finally, the propagation and modal content of internal tides can additionally be altered by interactions with the shear, strain and varying stratification present in mesoscale eddies, equatorial jets and other background ocean currents $[107,108,109,110,111,112]$. The interactions can potentially transfer energy to higher modes, leading to dissipation, or transfer energy between low-mode internal tides and the background ocean currents. Additional observational studies of low-mode internal tide energy loss via interactions with background currents are needed, since the significance of such interactions for internal tide-driven mixing is not yet well known.

Global estimates of the distribution of mode-1 internal tide energy dissipation suggest that largescale topographic obstacles cause the bulk of that dissipation [91, 63]. Using Lagrangian tracking of energy beams and parameterized energy sinks, it has been estimated that wave-wave interactions explain about $25 \%$ of mode-1 dissipation, but $65-80 \%$ of the overall modes $1-5$ dissipation [63]. Hence, despite major topographic features hosting the bulk of mode- 1 dissipation, much of the observed open-ocean internal tide dissipation may originate from the far-field dissipation of modes 2-5. Scattering by abyssal hills could be responsible for about $10 \%$ of the dissipation of the first five modes [63]. However, additional constraints on attenuation rates of low-mode internal tides by wave-wave interactions, and improved understanding of interactions with rough topography and background currents, are called for to narrow down uncertainties in these exploratory estimates.

\section{Wind}

Time-variable winds, often associated with passing storms, can provide power for near-inertial waves [G] (internal waves near the inertial frequency) to grow [113]. As storm activity increases in the winter, so does the energy in the near-inertial wave field and associated mixing rates, suggesting that winds are a key driver of the seasonal variability of internal wave-driven mixing in the ocean 
$[114,115]$. However, the main mechanisms leading near-inertial waves to dissipate their energy are not yet well constrained, leaving ample opportunity for future work.

The following divides the lifecycle of near-inertial waves into a generation phase, namely how near-inertial energy injected into the mixed layer by the wind is transferred to the ocean interior, followed by an internal wave propagation and mixing phase. Note that this division is distinct from conceptually partitioning the wave's lifecyle into an active wind-forcing phase, followed by the ocean's response after the forcing ends - a framework employed by some studies of isolated events $[116]$

7.1. Generation. Time-varying wind stress on the ocean surface due to synoptic events, such as a passing mid-latitude storm $[116]$ or cyclone $[117,118,119]$, can generate a resonant response in the mixed layer of water oscillating horizontally at a frequency close to inertial. The signature of nearinertial oscillations can be observed in the circles traced by surface drifters distributed beneath a storm [116]. One way that inertial oscillations decay is through energy dissipation by shear-driven turbulence close to the mixed layer base $[120,121]$; however, the importance of this mechanism is poorly known. The second, potentially more important, mechanism is downward energy radiation into the stratified interior ocean. Specifically, internal waves are radiated downward when horizontal variability in the magnitude of near-inertial velocities creates divergences and convergences within the mixed layer, generating pressure gradients that allow water to locally rise and fall at the inertial frequency, thereby radiating energy [122] (Figure 5).

The portion of near-inertial energy escaping the mixed layer as internal waves is not well constrained. Combining two lower-bound observational estimates of the fraction of energy propagating away as low-mode [123] and high-mode [124] waves suggests that a minimum of $27-53 \%$ of the energy input into near-inertial oscillations radiates away as internal waves. Roughly consistent with this observation, seasonal cycles in the mixed-layer and deep-ocean near-inertial kinetic energy are 
all similar in magnitude $[114,125]$. However, global modeling studies find that a smaller fraction of the wind work on near-inertial motions radiates downward, with estimates of $11-30 \%$ leaving the vicinity of the mixed layer $[126,127,128]$. Modeling studies with high spatio-temporal resolution suggest that resolving the interactions between the mesoscale eddy field and inertial oscillations may be important [129]; however, more work is needed to improve and reconcile observational and model-based estimates of downward near-inertial energy propagation.

Advancing our understanding of how the growth and decay of near-inertial oscillations can be modified by the background oceanic environment may help constrain the magnitude of energy leaving the mixed layer. For example, spatial variations in the Coriolis frequency may reduce the internal wave length scales [116], increasing the rate at which near-inertial energy drains from the mixed layer. Additionally, as near-inertial oscillations grow, energy transfer can occur with the background flow due to strong horizontal convergence [130], and horizontal strain [131] at a rate modulated by anticyclonic rotation $[132,131]$. During the decay of near-inertial oscillations, strong gradients in vorticity can increase the radiation of near-inertial energy from the mixed layer [133], especially at sharp gradients in the background currents [134, 133, 135].

Global studies commonly target a specific phase of the near-inertial wave generation process: the energy flux from winds to near-inertial oscillations. Estimates of the power available for nearinertial wave generation are often made using atmospheric reanalysis-derived winds to force general circulation models $[136,137]$, and 1-d slab models where the mixed layer is set to a fixed depth and energy radiates away at an assigned timescale $[113,116,138,139,140]$. The slab model produces estimates that agree well with observations, with caveats $[140,141]$. Products with relatively high temporal and spatial resolutions (reanalysis winds available at least every 4 hours, and satellite altimetric data sets with 1 degree horizontal resolution or finer) yield 0.9-1.4 TW of global power input from the winds [142, 137], while estimates from coarser temporal and/or spatial resolution winds suggest $0.3-1$ TW $[143,142,139,136,137]$. Both of these estimates are consistent with the 
first drifter-based estimate that finds a lower bound of $0.3 \mathrm{TW}$ [144]; however, more observational work is needed to reduce the large uncertainties in all estimates.

7.2. Local and Far field Mixing. Distinct high-mode near-inertial waves can be observed as bands of alternating shear at vertical scales of metres to hundreds of metres. In the North Pacific, observations reveal that high-mode near-inertial waves can attain vertical group velocities of 7 $23 \mathrm{~m} /$ day [124] and horizontal scales of 10s to 100s of kilometers [145]. Observational estimates indicate that the fraction of wind work on mixed layer oscillations that propagates away as highmode near-inertial waves may range between 12-33\% (reaching $800 \mathrm{~m}$ )[124], or 2-33\% (reaching 100 $\mathrm{m})[146]$. Modelling studies provide the slightly smaller estimate that $10 \%$ [127] of the wind work on the mixed layer reaches $230 \mathrm{~m}$ as high-mode internal waves.

In addition to high-mode internal waves, a large fraction of near-inertial energy is thought to radiate away as low modes, with estimates ranging from $15-20 \%$ of the energy input into mixed layer oscillations [123], to $33-45 \%$ of the near-inertial wave energy in the thermocline (modes 1-2) [116]. Since the Coriolis frequency decreases towards the equator and sets the internal wave lowfrequency limit, near-inertial waves are typically constrained to propagate equatorward [147, 123] except in strongly sheared background flows [148]. As the low modes propagate, they are subject to wave-wave interactions, including parametric subharmonic instability $[149,150]$, that can reduce their length scales and lead to turbulent mixing.

Near-inertial wave activity is elevated beneath mid-latitude storm tracks, with a seasonal cycle that peaks in the winter months from the surface to the seafloor $[114,151]$ (Figure 5 a-b); however, the mechanisms underpinning such a deep seasonal cycle are not well understood. The stronger near-inertial wave activity during the winter months is correlated with an enhancement of inferred diapycnal mixing $[48,152,115]$ to at least a depth of $2 \mathrm{~km}$ (Figure $5 \mathrm{c}-\mathrm{d}$ ). Future work linking direct observations of mixing using microstructure methods to the seasonal cycle in near-inertial 
kinetic energy would be valuable to corroborate the implication of near-inertial waves in driving seasonality in mixing.

The mesoscale flow field likely shapes the rate of near-inertial propagation and spatial distribution of the energy dissipation, in addition to influencing the generation processes described in the previous subsection. Modelling and theory suggest that the mesoscale vorticity can reduce the horizontal scales of the waves and funnel near-inertial energy into regions of anticyclonic vorticity $[153,154,155,156,129]$. Additionally, a positive strain rate in the mesoscale current field can substantially alter the length scales and propagation velocities of internal waves $[32,109,53]$. Finally, internal waves can encounter critical layers along steeply sloping isopycnals, triggering energy dissipation $[157,153,158,159]$. Observations support these general ideas, finding altered internal waves and elevated dissipation rates at the boundaries of individual mesoscale eddies $[160,161,162,163,164]$, and relatively large inferred mixing in response to increased wind activity in the presence of an energetic mesoscale eddy field [115].

\section{Geostrophic Currents}

Winds provide about $1 \mathrm{TW}$ of power to the geostrophic current field in the ocean [165, 166]. A portion of the energy in ocean currents is then transferred to the internal wave field through interactions with topographic features, or by direct generation of internal waves. However, it has been suggested that the bulk of the energy in the geostrophic current field is not dissipated through internal wave processes, but by a combination of bottom friction $[167,168]$, hydraulic effects downstream of topography [169], and suppression by wind work [8, 170].

\subsection{Quasi-steady lee wave generation at topographic features. When steady or eddying} abyssal flows impinge on small-scale topographic features, they can generate internal waves, often called lee waves $[\mathrm{G}][19]$. Internal lee waves have frequencies and length scales set by the velocity of the currents and length scales of the bathymetry. Estimates made using linear wave theory [19] 
of the total global energy transfer rate from geostrophic currents into internal lee waves range from 0.15 to 0.75 TW $[171,172,173,174,175]$, with a major contribution from the Antarctic Circumpolar Current (ACC) region. These estimates' large range arises from uncertainties in ocean stratification, bathymetric products and, principally, the representation of near-bottom current speeds in global circulation models $[173,176]$.

Once generated, lee waves can travel upwards if the frequency in the wave's reference frame is between $f$ and $N$. In a steady current, propagating lee waves appear stationary in the ground reference frame, but can shift upstream or downstream if the current varies in time or nonlinear interactions are present $[19,177]$. Most of the evidence for lee wave activity in the ACC has been provided by indirect measurements of elevated upward-propagating internal wave energy in the deepest 1-2 km of the water column [178, 179, 180]; however, an unambiguous observation was made of the waves themselves [181] (Figure 6a). Observations in the western boundaries of midlatitude ocean basins also show evidence for the generation and propagation of internal lee waves there [182]. Lee wave radiation is highly intermittent due to changes in the intensity and position of the background flow, resulting in temporal variability of the lee wave field on time scales up to decadal [183, 184, 185].

Lee waves' energy is dissipated as the waves encounter critical layers, or as the energy is transferred to other waves via wave-wave interactions or reabsorbed into the background current field [186]. Observations of elevated turbulence attributed to lee waves include studies in the ACC [187, 188, 178, 179, 180], abyssal passages [189], and canyons [190]. Estimates of the amount of radiated lee wave energy that is dissipated within $1 \mathrm{~km}$ of the bottom range from up to $50 \%$ using 2-d models [191] to 2-30\% using observations [178, 179]. The discrepancy between these estimates highlights that lee waves do not play as important a role in the internal wave global energy budget as early modeling studies suggested. Additional complexity, such as including 3-d flow effects, 
is necessary to model lee wave generation, propagation, and dissipation more accurately than in current modelling efforts $[47,174,179,192,169,177,186]$.

\subsection{Internal wave generation from geostrophic currents. The generation of internal waves} directly from the geostrophic current field may contribute to sustaining turbulent dissipation and mixing, although the contribution may be relatively small. Modelling results demonstrate that internal waves near the inertial frequency can be generated through resonance with the rapidly varying components of background currents $[193,194,195,196]$ and, more specifically, during intense straining of small-scale fronts by the larger-scale currents [197, 198, 199]. Additionally, an actively unstable front might radiate internal waves with a larger range of frequencies [200, 201]. Finally, geostrophic currents can also transfer energy to existing near-inertial waves, providing an additional energy pathway $[202,203]$. Estimates of the global energy flux from geostrophic currents to internal waves range between 0.1 and $0.36 \mathrm{TW}[8,204,198]$. However, only limited observations of this internal wave generation pathway exist $[205,198]$, so the prevalence of these processes is still unclear.

The eventual fate of the internal waves drawing energy from geostrophic flows is either turbulent dissipation (Figure 6b) or re-absorption into the background current field. If a substantial portion of the energy from these internal waves dissipates via wave breaking, then the waves may be a significant energy sink for the mesoscale eddy field [206]. However, modelling results suggest that only around $15 \%$ [198] or 30\% [207] of the energy is dissipated through turbulence, with the remainder returning to the background current field. The low fraction of dissipated energy indicates that the internal waves generated from ocean currents may be an important mechanism for redistributing energy, but contribute only modestly to the global internal wave and mesoscale eddy kinetic energy budgets. 
All the processes governing the generation, propagation, and dissipation of internal waves deriving their energy from tides, winds and geostrophic currents conspire to shape the global distribution of the turbulent dissipation rate and diapycnal diffusivity as observed using microstructure [62] and finestructure $[60,61,9,115]$ measurements (Figure 7a). The intensity of the dissipation rate and diffusivity both range over three orders of magnitude across the globe, so that the bulk of the values span $10^{-11}-10^{-8}[\mathrm{~W} / \mathrm{kg}]$ and $10^{-6}-10^{-3}\left[\mathrm{~m}^{2} / \mathrm{s}\right]$, respectively $[60,61,62]$. When the bottom topography is rough, the dissipation rate is often elevated by an order of magnitude or more from the seafloor to near the surface, due to near-field dissipation of internal tides or lee waves as well as mixing from topographic scattering of remotely generated internal waves $[60,61,106]$. Regions with strong sources of tidal and wind energy are also associated with elevated dissipation rates, indicating that near-field dissipation plays an important role in shaping the global geography of mixing $[115,68]$. For example, mixing is elevated above the Hawaiian Ridge, Southwest Indian Ridge and Mid-Atlantic Ridge due to tidal generation and scattering [82, 75, 63]. In the Southern Ocean around the Kerguelen Plateau and Macquarie Ridge, lee waves and tides may both contribute [178, 174, 92].

As explained in the following, mixing from internal waves contributes to sustaining the deep ocean's meridional overturning circulation, and importantly influences the broader global climate system, in addition to impacting the oxygen distribution [12], the delivery of nutrients to the ocean's surface layers [14], and primary production [12].

9.1. Global Overturning Circulation. The cold, dense water that sinks to the ocean abyss at high latitudes must eventually rise, returning to the ocean surface and thereby closing the Meridional Overturning Circulation (MOC). The simplified model of the MOC has two major 
branches. One of the branches transports deep water southward, and is primarily driven by windinduced upwelling in the Southern Ocean [208], although in models its strength is sensitive to changes in mixing $[209,210,211,129]$. The second branch, in turn, transports abyssal water northward and upward [4], and is thought to be largely driven by internal wave mixing $[3,62,5,6]$, with additional contributions from geothermal heating along the seafloor [212, 213] and mixing along the deep western boundaries [214] and within constrictive passages [215].

In the northward branch of the abyssal MOC, turbulence from breaking internal waves transfers buoyancy downward, progressively transforming the dense bottom water into lighter water. This lightening enables new inflowing water to intrude below, such that the transformed water rises above the new water, creating the upward branch of the abyssal MOC. The strength of this branch has been estimated to be 20-30 Sverdrups (Sv; $\left.1 \mathrm{~Sv} \equiv 10^{6} \mathrm{~m}^{3} \mathrm{~s}^{-1}\right)[216,217,4]$. Internal tides are thought to drive a substantial portion of the abyssal upwelling, with estimates including both near-field and far-field mixing that range between the entirety of the abyssal MOC transport to 7 $\mathrm{Sv}[218,5]$, or $5 \mathrm{~Sv}$ with a spatially variable mixing efficiency [219]. Lee waves contribute a smaller portion of the abyssal upwelling, with estimates ranging between 2-3 Sv $[220,5]$. It is not known if near-inertial waves play a significant role in driving the abyssal MOC. Both the horizontal and vertical distributions of mixing alter the magnitude and vertical structure of the MOC in models $[221,222,218,209,223,220,210]$, an example of which is shown in Figure $7 \mathrm{~b}$, indicating that the global spatial variability (Figure 7 a) is important for setting the observed properties of the MOC.

9.2. Climate. The broader climate system is sensitive to the distribution and magnitude of internal wave-driven mixing in the ocean, beyond the role of mixing in driving the MOC as discussed in the previous subsection. Since diffusivity from internal waves cannot be explicitly captured by global models, parameterizations are currently being developed to include the effects of the spatiotemporally varying diffusivity [21]. To explore how sensitive the ocean and atmosphere are to 
mixing from breaking internal waves, climate models are run with a range of parameterizations designed to represent mixing from the tides [106, 210, 224, 225], winds [106, 226, 225] and lee waves $[220,227]$, in addition to changing the magnitude of the model-prescribed background diffusivity [211]. These studies report that even small perturbations in the magnitude or distribution of the diffusivity in global models can lead to substantial changes in the temperature, circulation, and fluxes in the atmosphere and ocean. However, both the magnitude and the sign of these changes vary between studies due to the range of mixing parameterizations and the details of each model, thus the following focuses on the broad trends across all studies.

Altering the diffusivity changes the vertical profiles and horizontal distribution of temperature and salinity throughout the ocean, and therefore the density and stratification $[226,220,227,210$, $224,211,225]$. The ocean's meridional heat transport is also sensitive to changing background diffusivity and to the spatial distribution of mixing from internal tides [210, 211], but not to parameterized mixing induced by near-inertial waves in one study that underestimates the magnitude of mixing from the wind [226]. Changes in the properties and circulation of the ocean interior lead to variations in the sea surface temperature [226, 210, 211, 225], mixed layer depth [226, 224], and air-sea fluxes [129, 211]. Perturbing interior diffusivity also has repercussions above the sea surface, including sea ice extent and concentration [226, 224, 211], air temperature, atmospheric circulation, and precipitation [226, 224, 211, 225]. For example, one study added diffusivity from near-inertial internal waves and found notable changes in the sea ice extent and surface heat flux (Figure 7c)[226]. The substantial sensitivity of both the ocean and the atmosphere to internal wave mixing indicates that including its effects in climate-scale models is important for a realistic representation of the climate system.

Beyond these widespread climatic impacts, internal wave mixing has been shown to exert a profound influence on regional and global climate via its localised effects on several important elements of the global ocean circulation. For example, the vertical density structure in the Indonesian Seas 
is sensitive to the representation of tidal mixing in models - with implications for a range of aspects of (sub-)tropical Indo-Pacific climate including volume transport of the Indonesian Throughflow, ocean heat uptake, and rainfall $[228,229,230]$. In the equatorial Pacific, parameterizing internal wave mixing in the thermocline yields changes in the equatorial upwelling, sea surface temperature, and wind patterns $[226,225]$. However, only representing mixing from tides or lee waves has a negligible effect [220, 210], suggesting that including more processes than current tide and lee wave parameterizations represent may be necessary to accurately model the equatorial Pacific. Finally, the latitudinal distribution of deep mixing from lee waves and tides has been argued to alter the ACC transport, the depth of the ocean thermocline and, by extension, many important features of global climate $[231,232,220]$. As the operation of internal wave mixing in other pivotal elements of the global ocean circulation is further unravelled, it is likely that more climatic impacts of localised mixing will emerge.

\section{Summary And Future Directions}

Global and regional patterns of internal wave-driven turbulent mixing are controlled by the complex and convoluted processes of internal wave generation, propagation, interaction and dissipation. Internal waves act as a conduit, eventually funneling energy from tides, winds, and currents into turbulence, leading to both energy dissipation and mixing. In turn, the mixing plays a role in driving the meridional overturning circulation and aids in setting many characteristics of the global climate. While much progress has been made recently in understanding significant elements of all stages of the internal wave lifecycle, several fundamental knowledge gaps remain. Here, we synthesize these gaps into three broad priority challenges, which we encourage the oceanographic community to address in coming years.

The first challenge entails advancing our understanding of the processes that transfer energy within the internal wave field, and which ultimately lead to dissipation and mixing. As discussed 
here, investigations have improved constraints on the wave field's energy sources, and the magnitude and placement of wave energy dissipation. However, the physics of how the energy is transferred across length scales and frequencies along the pathway to dissipation is poorly understood. In particular, we do not know why the observed internal wave spectrum varies only modestly in shape across the global ocean [53]. Important likely candidates include wave-wave interactions [29, 26], topographic scattering and reflection [93], and interactions with the background current field [233]. Studies focused on these individual energy transfer processes, and on how they combine to form the observed internal wave spectrum, would be valuable. For example, recent investigations suggest that parametric subharmonic instability, the very efficient type of wave-wave interaction, is not sufficient to explain the majority of the down-scale internal wave energy transfer [29], indicating that other wave-wave interactions [26] or wave-wave interactions in the context of geostrophic currents [83] may be important in shaping the spectrum. Additional theoretical and numerical work constraining attenuation due to wave-wave interactions using an internal wave spectrum close to that observed in the ocean is especially needed [38, 29].

The second challenge concerns unravelling how internal waves interact with other types of ocean currents, and how these interactions shape the distribution of mixing in the ocean. Interactions between internal waves and currents deserve special consideration, since among the energy exchange processes depicted schematically in Figure 3 and discussed in challenge one, they have the largest uncertainties. The mildest form of this interaction is a gradual shift in the wave phase as waves travel through a current field; for example, this de-phasing may occur as low-mode internal tides propagate through a variable mesoscale flow. De-phasing of low modes renders them invisible to detection by satellite altimetry, increasing the uncertainty in estimates of low-mode attenuation and subsequent energy dissipation [111, 234, 235]. An improved understanding of the weak modulation of internal waves by background currents is needed, especially with a view to constraining low-mode internal tide attenuation and dissipation in global models [210, 63]. 
Moderate interactions involve the impact of spatio-temporal variability of background currents, which present a variable medium for internal waves to exist in and propagate through. Background current flow and vorticity affect internal wave generation by, for example, altering the rate of energy transfer to both internal lee waves and wind-driven near-inertial internal waves. Then, as waves propagate, structure in the background current shear, strain or stratification can lead to significant wave refraction, reflection or, in extreme cases, wave breaking as propagation slows down to a halt in critical layers or sharp fronts. Theoretical, modelling and observational studies are needed to understand the influence of these moderate interactions on the generation, propagation, and dissipation of internal waves, in addition to their prevalence in the ocean and cumulative impact on energy pathways.

The strongest form of interaction involves substantial two-way energy exchanges between internal waves and geostrophic flows. For example, for internal lee waves, accurate understanding of refraction in sheared background flows like the ACC is key to predict where and how the waves will deposit their momentum to accelerate or decelerate the background flow [236]. Two-way energy exchanges between internal waves and background flows are also likely to be important where the spatio-temporal scales of both classes of flows overlap, for example in submesoscale $(0.1-10 \mathrm{~km}$ scales) flows on the edges of mesoscale eddies, or near-inertial waves with slow group velocities and large horizontal wavelengths. The small-scale and quickly varying energy exchanges in these settings are extremely difficult to observe, calling for the development of new, multi-platform measurement approaches and numerical simulations of increased complexity. We anticipate that a step change in understanding of how the ocean's mesoscale eddy field loses its energy to internal waves and turbulence will result in major improvements in the realism of climate-scale ocean models, some of whose key features (for example, deep-ocean MOC, ACC transport, stratification) are now understood to depend on the eddy-internal wave energy transfer [206]. 
Building on these challenges, the overarching (and arguably most daunting) task is to reformulate internal wave-driven mixing as a fully interactive component of ocean circulation and the climate system [106], rather than the essentially passive and unchanging diffusivity field as which wave mixing has been traditionally viewed. More work is needed to further develop parameterizations of mixing and quantify their effects on global ocean circulation and climate. For example, more studies are needed that include parameterized mixing from near-inertial waves and explore the impact of time-varying mixing so that feedbacks on the climate system are represented. To drive this transformation, we require new ways to measure internal wave mixing over the annual or longer time scales that are most climatically relevant. In addition, the next generation of physically robust representations of the key wave mixing processes will need to be incorporated into climate-scale ocean models. The spark for this shift in view has been lit by a number of recent studies mentioned in this review, but much work remains to be done for the shift to be realized.

\section{Glossary of Key terms}

Internal wave orthogonal modes: Theoretical framework used to describe the vertical structure of internal waves, where low-mode internal waves have larger vertical scales and high-mode internal waves have smaller vertical scales.

Buoyancy frequency (N): The oscillation frequency of a vertically displaced water parcel, which scales with the local vertical stratification gradient.

Coriolis/inertial frequency (f): The oscillation frequency of a horizontally displaced water parcel influenced solely by the earth's rotation and defined by $2 \Omega \sin \phi$, where $\Omega$ is the angular velocity of the earth and $\phi$ is the latitude.

Turbulent kinetic energy dissipation rate $(\epsilon)$ : Rate of energy dissipation due to viscosity with units $\mathrm{W} \mathrm{kg}^{-1}$.

Diapycnal diffusivity (K): Diffusivity across density surfaces with units $\mathrm{m}^{2} \mathrm{~s}^{-1}$. 
Barotropic tides: Nearly full-depth periodic rise and fall of ocean water due to the gravitational attraction of the moon and sun.

Baroclinic/internal tides: Depth-varying oscillations at tidal frequencies arising from barotropic tides impinging on topographic features.

Near-Inertial internal waves: Internal waves at or near the Coriolis/inertial frequency, often but not always generated by the wind.

Lee waves: Internal waves often generated by deep geostrophic flow encountering topographic features.

(1)

\section{ACKNOWLEDGements}

This work was supported by the National Aeronautics and Space Administration award 80NSSC19K1116 and National Science Foundation award OCE-1923558. ACNG acknowledges the support of the Royal Society and Wolfson Foundation. writing.

CW led the design and writing of the review. CL, ANG, JK, JM, and KS all contributed to the

The authors declare no competing interests.

\section{Competing Interests}

References

[1] Fer, I., Voet, G., Seim, K. S., Rudels, B. \& Latarius, K. Intense mixing of the Faroe Bank Channel overflow. Geophys. Res. Lett. 37 (2010).

[2] D'Asaro, E. A. Turbulence in the upper-ocean mixed layer. Annu. Rev. Mar. Sci. 6, 101-115 (2014).

[3] Munk, W. \& Wunsch, C. Abyssal recipes II: energetics of tidal and wind mixing. Deep-Sea Res. I 45, 1977-2010 (1998). 
[4] Talley, L. D. Closure of the global overturning circulation through the Indian, Pacific, and Southern Oceans: Schematics and transports. Oceanogr. 26, 80-97 (2013).

[5] de Lavergne, C., Madec, G., Le Sommer, J., Nurser, A. G. \& Naveira Garabato, A. C. On the consumption of Antarctic Bottom Water in the abyssal ocean. J. Phys. Oceanogr. 46, 635-661 (2016).

[6] Kunze, E. The internal-wave-driven meridional overturning circulation. J. Phys. Oceanogr. 47, 2673-2689 (2017).

[7] Wunsch, C. \& Ferrari, R. Vertical mixing, energy, and the general circulation of the oceans. Annu. Rev. Fluid Mech. 36, 281-314 (2004).

[8] Ferrari, R. \& Wunsch, C. Ocean Circulation Kinetic Energy: Reservoirs, Sources, and Sinks. Ann. Rev. Fluid Mech. 41, 253-282 (2009).

[9] Kunze, E. Internal-Wave-Driven Mixing: Global Geography and Budgets. J. Phys. Oceanogr. 47, 1325-1345 (2017).

[10] Anderson, L. A. \& Sarmiento, J. L. Redfield ratios of remineralization determined by nutrient data analysis. Global Biogeochem. Cycles 8, 65-80 (1994).

[11] Sarmiento, J. L., Gruber, N., Brzezinski, M. \& Dunne, J. High-latitude controls of thermocline nutrients and low latitude biological productivity. Nature 427, 56 (2004).

[12] Friedrich, T., Timmermann, A., Decloedt, T., Luther, D. \& Mouchet, A. The effect of topography-enhanced diapycnal mixing on ocean and atmospheric circulation and marine biogeochemistry. Ocean Modelling 39, $262-274(2011)$.

[13] Deutsch, C. \& Weber, T. Nutrient ratios as a tracer and driver of ocean biogeochemistry. Annu. Rev. Mar. Sci. 4, 113-141 (2012).

[14] Tuerena, R. E. et al. Internal tides drive nutrient fluxes into the deep chlorophyll maximum over mid-ocean ridges. Global Biogeochem. Cycles (2019).

[15] Sharples, J. Internal tides drive nutrient fluxes into the deep chlorophyll maximum over mid-ocean ridges. Global Biogeochem. Cycles (2019).

[16] Phillips, O. M. The dynamics of the upper ocean (CUP Archive, 1966).

[17] Woods, J. Wave-induced shear instability in the summer thermocline. J. Fluid Mech. 32, 791-800 (1968).

[18] Garrett, C. \& Munk, W. Internal waves in the ocean. Annu. Rev. Fluid Mech. 11, 339-369 (1979).

[19] Bell, T. Topographically generated internal waves in the open ocean. J. Geophys. Res. 80, 320-327 (1975). 
[20] Munk, W. H. Abyssal recipes. In Deep-Sea Res. Oceanogr. Abstr., vol. 13, 707-730 (Elsevier, 1966).

[21] MacKinnon, Z., Jennifer A Zhao et al. Climate Process Team on Internal-Wave Driven Ocean Mixing. Bull. Am. Meteorol. Soc. 98, 2429-2454 (2017).

[22] Alford, M. H., MacKinnon, J. A., Simmons, H. L. \& Nash, J. D. Near-inertial internal gravity waves in the ocean. Annu. Rev. Mar. Sci. 8, 95-123 (2016).

[23] Gill, A. E. Atmosphere-ocean dynamics (Elsevier, 2016).

[24] Olbers, D. J. Nonlinear energy transfer and the energy balance of the internal wave field in the deep ocean. $J$. Fluid Mech. 74, 375-399 (1976).

[25] Lvov, Y. V., Polzin, K. L. \& Yokoyama, N. Resonant and near-resonant internal wave interactions. J. Phys. Oceanogr. 42, 669-691 (2012).

[26] Eden, C., Pollmann, F. \& Olbers, D. Numerical evaluation of energy transfers in internal gravity wave spectra of the ocean. J. Phys. Oceanogr. 49, 737-749 (2019).

[27] Hibiya, T., Nagasawa, M. \& Niwa, Y. Nonlinear energy transfer within the oceanic internal wave spectrum at mid and high latitudes. J. Geophys. Res. Oceans: Oceans 107, 28-1 (2002).

[28] MacKinnon, J. A. et al. Parametric subharmonic instability of the internal tide at 29 N. J. Phys. Oceanogr. 43, 17-28 (2013).

[29] Olbers, D., Pollmann, F. \& Eden, C. On PSI interactions in internal gravity wave fields and the decay of baroclinic tides. J. Phys. Oceanogr. (2020).

[30] Jones, W. L. Ray tracing for internal gravity waves. J. Geophys. Res. 74, 2028-2033 (1969).

[31] Staquet, C. \& Sommeria, J. Internal gravity waves: from instabilities to turbulence. Annu. Rev. Fluid Mech. 34, 559-593 (2002).

[32] Bühler, O. \& McIntyre, M. E. Wave capture and wave-vortex duality. J. Fluid Mech. 534, 67-95 (2005).

[33] Thorpe, S. Models of energy loss from internal waves breaking in the ocean. J. Fluid Mech. 836, 72-116 (2018).

[34] van Haren, H. Instability observations associated with wave breaking in the stable-stratified deep-ocean. PHYSICA D 292, 62-69 (2015).

[35] Gregg, M. C., Seim, H. E. \& Percival, D. B. Statistics of shear and turbulent dissipation profiles in random internal wave-fields. J. Phys. Oceanogr. 23, 1777-1799 (1993).

[36] Alford, M. H. \& Pinkel, R. Observations of overturning in the thermocline: The context of ocean mixing. J. Phys. Oceanogr. 30, 805-832 (2000). 
[37] Olbers, D. J. Models of the oceanic internal wave field. Reviews of Geophysics 21, 1567-1606 (1983).

[38] Onuki, Y. \& Hibiya, T. Decay rates of internal tides estimated by an improved wave-wave interaction analysis. J. Phys. Oceanogr. 48, 2689-2701 (2018).

[39] Osborn, T. R. Estimates of the local-rate of vertical diffusion from dissipation measurements. J. Phys. Oceanogr. 10, 83-89 (1980).

[40] Gregg, M., D’Asaro, E., Riley, J. \& Kunze, E. Mixing efficiency in the ocean. Annu. Rev. Mar. Sci. 10, $443-473$ (2018).

[41] Oakey, N. Determination of the rate of dissipation of turbulent energy from simultaneous temperature and velocity shear microstructure measurements. J. Phys. Oceanogr. 12, 256-271 (1982).

[42] Gregg, M. Uncertainties and limitations in measuring $\varepsilon$ and $\chi$ t. J. Atmos. Ocean. Technol.Annu. Rev. Fluid Mech. 16, 1483-1490 (1999).

[43] Henyey, F. S., Wright, J. \& Flatte, S. M. Energy and action flow through the internal wave feild - an eikonal approach. J. Geophys. Res.-Oceans 91, 8487-8495 (1986).

[44] Gregg, M. C. Scaling turbulent dissipation in the thermocline. J. Geophys. Res.-Oceans 94, 9686-9698 (1989).

[45] Polzin, K. L., Toole, J. M. \& Schmitt, R. W. Finescale parameterizations of turbulent dissipation. J. Phys. Oceanogr. 25, 306-328 (1995).

[46] Polzin, K. L., Naveira Garabato, A. C., Huussen, T. N., Sloyan, B. M. \& Waterman, S. N. Finescale parameterizations of turbulent dissipation. J. Geophys. Res.-Oceans 119 (2014).

[47] Waterman, S., Polzin, K. L., Naveira Garabato, A. C., Sheen, K. L. \& Forryan, A. Suppression of internal wave breaking in the Antarctic Circumpolar Current near topography. J. Phys. Oceanogr. 44 (2014).

[48] Whalen, C. B., MacKinnon, J. A., Talley, L. D. \& Waterhouse, A. F. Estimating the mean diapycnal mixing using a finescale strain parameterization. J. Phys. Oceanogr. 45, 1174-1188 (2015).

[49] McComas, C. H. \& Müller, P. The dynamic balance of internal waves. J. Phys. Oceanogr. 11, 970-986 (1981).

[50] Garrett, C. \& Munk, W. Space-time scales of internal waves - progress report. J. Geophys. Res. 80, 291-297 (1975).

[51] Munk, W. Internal waves and small-scale processes, Evolution of Physical Oceanography BA Warren, C. Wunsch, 264-291 (1981).

[52] Müller, P. \& Liu, X. Scattering of internal waves at finite topography in two dimensions. Part I: Theory and case studies. J. Phys. Oceanogr. 30, 532-549 (2000). 
[53] Polzin, K. L. \& Lvov, Y. V. Toward regional characterizations of the oceanic internal wavefield. Rev. Geophys. 49 (2011).

[54] Lien, R.-C., Tang, T., Chang, M. \& d'Asaro, E. Energy of nonlinear internal waves in the South China Sea. Geophys. Res. Lett. 32 (2005).

[55] Levine, M. D. A modification of the garrett-munk internal wave spectrum. J. Phys. Oceanogr. 32, 3166-3181 (2002).

[56] MacKinnon, J. \& Gregg, M. Shear and baroclinic energy flux on the summer new england shelf. J. Phys. Oceanogr. 33, 1462-1475 (2003).

[57] Garrett, C. \& Kunze, E. Internal tide generation in the deep ocean. Annu. Rev. Fluid Mech. 39, 57-87 (2007).

[58] Egbert, G. \& Ray, R. Significant dissipation of tidal energy in the deep ocean inferred from satellite altimeter data. Nature 405, 775 (2000).

[59] Nycander, J. Generation of internal waves in the deep ocean by tides. J. Geophys. Res. Oceans: Oceans 110 (2005).

[60] Kunze, E., Firing, E., Hummon, J. M., Chereskin, T. K. \& Thurnherr, A. M. Global abyssal mixing inferred from lowered ADCP shear and CTD strain profiles. J. Phys. Oceanogr. 36, 1553-1576 (2006).

[61] Whalen, C. B., Talley, L. D. \& MacKinnon, J. A. Spatial and temporal variability of global ocean mixing inferred from Argo profiles. Geophys. Res. Lett. 39 (2012).

[62] Waterhouse, A. F. et al. Global patterns of diapycnal mixing from measurements of the turbulent dissipation rate. J. Phys. Oceanogr. 1854-1872 (2014).

[63] de Lavergne, C. et al. Toward global maps of internal tide energy sinks. Ocean Modelling 137, 52-75 (2019).

[64] Egbert, G. D. \& Ray, R. D. Estimates of m2 tidal energy dissipation from TOPEX/Poseidon altimeter data. J. Geophys. Res. Oceans: Oceans 106, 22475-22502 (2001).

[65] Nakamura, T., Isoda, Y., Mitsudera, H., Takagi, S. \& Nagasawa, M. Breaking of unsteady lee waves generated by diurnal tides. Geophys. Res. Lett. 37 (2010).

[66] Nash, J. D. \& Moum, J. N. Internal hydraulic flows on the continental shelf: High drag states over a small bank. J. Geophys. Res. Oceans: Oceans 106, 4593-4611 (2001).

[67] St. Laurent, L. \& Garrett, C. The role of internal tides in mixing the deep ocean. J. Phys. Oceanogr. 32, 2882-2899 (2002).

[68] Vic, C. et al. Deep-ocean mixing driven by small-scale internal tides. Nat. Commun. 10 (2019). 
[69] Falahat, S., Nycander, J., Roquet, F. \& Zarroug, M. Global calculation of tidal energy conversion into vertical normal modes. J. Phys. Oceanogr. 44, 3225-3244 (2014).

[70] Zhao, Z., Alford, M. H., Girton, J. B., Rainville, L. \& Simmons, H. L. Global observations of open-ocean mode-1 M2 internal tides. J. Phys. Oceanogr. 46, 1657-1684 (2016).

[71] Polzin, K. Idealized solutions for the energy balance of the finescale internal wave field. J. Phys. Oceanogr. 34, $231-246$ (2004).

[72] Melet, A. et al. Internal tide generation by abyssal hills using analytical theory. J. Geophys. Res. Oceans: Oceans 118, 6303-6318 (2013).

[73] Goff, J. A. \& Arbic, B. K. Global prediction of abyssal hill roughness statistics for use in ocean models from digital maps of paleo-spreading rate, paleo-ridge orientation, and sediment thickness. Ocean Modelling 32, $36-43(2010)$.

[74] Lefauve, A., Muller, C. \& Melet, A. A three-dimensional map of tidal dissipation over abyssal hills. J. Geophys. Res. Oceans: Oceans 120, 4760-4777 (2015).

[75] Polzin, K. L., Toole, J. M., Ledwell, J. R. \& Schmitt, R. W. Spatial variability of turbulent mixing in the abyssal ocean. Science 276, 93-96 (1997).

[76] Ledwell, J. R. et al. Evidence for enhanced mixing over rough topography in the abyssal ocean. Nature 403, 179-182 (2000).

[77] Muller, C. J. \& Bühler, O. Saturation of the internal tides and induced mixing in the abyssal ocean. J. Phys. Oceanogr. 39, 2077-2096 (2009).

[78] Polzin, K. L. An abyssal recipe. Ocean Modelling 30, 298-309 (2009).

[79] Klymak, J. M., Legg, S. \& Pinkel, R. A simple parameterization of turbulent tidal mixing near supercritical topography. J. Phys. Oceanogr. 40, 2059-2074 (2010).

[80] Nikurashin, M. \& Legg, S. A mechanism for local dissipation of internal tides generated at rough topography. J. Phys. Oceanogr. 41, 378-395 (2011).

[81] St. Laurent, L. C. \& Nash, J. D. On the fraction of internal tide energy dissipated near topography. In Proceedings of the 13th 'Aha Huliko'a Hawaiian Winter Workshop, Honolulu, HI, University of Hawaii at Manoa (2004).

[82] Klymak, J. M. et al. An estimate of tidal energy lost to turbulence at the Hawaiian Ridge. J. Phys. Oceanogr. 36, 1148-1164 (2006). 
[83] Richet, O., Muller, C. \& Chomaz, J.-M. Impact of a mean current on the internal tide energy dissipation at the critical latitude. J. Phys. Oceanogr. 47, 1457-1472 (2017).

[84] Dushaw, B. D., Howe, B. M., Cornuelle, B. D., Worcester, P. F. \& Luther, D. S. Barotropic and baroclinic tides in the central North Pacific Ocean determined from long-range reciprocal acoustic transmissions. J. Phys. Oceanogr. 25, 631-647 (1995).

[85] Ray, R. D. \& Mitchum, G. T. Surface manifestation of internal tides generated near Hawaii. Geophys. Res. Lett. 23, 2101-2104 (1996).

[86] Zhao, Z. Mapping internal tides from satellite altimetry without blind directions. J. Geophys. Res. Oceans: Oceans 124, 8605-8625 (2019).

[87] Zhao, Z. The global mode-2 M2 internal tide. J. Geophys. Res. Oceans: Oceans 123, 7725-7746 (2018).

[88] Alford, M. H. \& Zhao, Z. Global patterns of low-mode internal-wave propagation. Part i: Energy and energy flux. J. Phys. Oceanogr. 37, 1829-1848 (2007).

[89] Zhao, Z., Alford, M. H., MacKinnon, J. A. \& Pinkel, R. Long-range propagation of the semidiurnal internal tide from the Hawaiian Ridge. J. Phys. Oceanogr. 40, 713-736 (2010).

[90] Vic, C. et al. The lifecycle of semidiurnal internal tides over the northern mid-atlantic ridge. J. Phys. Oceanogr. 48, 61-80 (2018).

[91] Kelly, S., Jones, N., Nash, J. \& Waterhouse, A. The geography of semidiurnal mode-1 internal-tide energy loss. Geophys. Res. Lett. 40, 4689-4693 (2013).

[92] Waterhouse, A. F. et al. Observations of the Tasman Sea internal tide beam. J. Phys. Oceanogr. 48, 1283-1297 (2018).

[93] Müller, P. \& Xu, N. Scattering of oceanic internal gravity waves off random bottom topography. J. Phys. Oceanogr. 22, 474-488 (1992).

[94] Bühler, O. \& Holmes-Cerfon, M. Decay of an internal tide due to random topography in the ocean. J. Fluid Mech. 678, 271-293 (2011).

[95] Johnston, T. S. \& Merrifield, M. A. Internal tide scattering at seamounts, ridges, and islands. J. Geophys. Res. Oceans: Oceans 108 (2003).

[96] Mathur, M., Carter, G. S. \& Peacock, T. Topographic scattering of the low-mode internal tide in the deep ocean. J. Geophys. Res. Oceans: Oceans 119, 2165-2182 (2014). 
[97] Klymak, J. M., Buijsman, M., Legg, S. \& Pinkel, R. Parameterizing surface and internal tide scattering and breaking on supercritical topography: the one-and two-ridge cases. J. Phys. Oceanogr. 43, 1380-1397 (2013).

[98] Johnston, T. S., Rudnick, D. L. \& Kelly, S. M. Standing internal tides in the Tasman Sea observed by gliders. J. Phys. Oceanogr. 45, 2715-2737 (2015).

[99] Legg, S. \& Adcroft, A. Internal wave breaking at concave and convex continental slopes. J. Phys. Oceanogr. 33, 2224-2246 (2003).

[100] Nash, J. D., Kunze, E., Toole, J. M. \& Schmitt, R. W. Internal tide reflection and turbulent mixing on the continental slope. J. Phys. Oceanogr. 34, 1117-1134 (2004).

[101] Martini, K. I., Alford, M. H., Kunze, E., Kelly, S. M. \& Nash, J. D. Internal bores and breaking internal tides on the Oregon continental slope. J. Phys. Oceanogr. 43, 120-139 (2013).

[102] Legg, S. Scattering of low-mode internal waves at finite isolated topography. J. Phys. Oceanogr. 44, 359-383 (2014).

[103] Ansong, J. K. et al. Geographical distribution of diurnal and semidiurnal parametric subharmonic instability in a global ocean circulation model. J. Phys. Oceanogr. 48, 1409-1431 (2018).

[104] Hibiya, T. \& Nagasawa, M. Latitudinal dependence of diapycnal diffusivity in the thermocline estimated using a finescale parameterization. Geophys. Res. Lett. 31 (2004).

[105] Hazewinkel, J. \& Winters, K. PSI of the internal tide on a $\beta$ plane: flux divergence and near-inertial wave propagation. J. Phys. Oceanogr. 41, 1673-1682 (2011).

[106] Eden, C. \& Olbers, D. An energy compartment model for propagation, nonlinear interaction, and dissipation of internal gravity waves. J. Phys. Oceanogr. 44, 2093-2106 (2014).

[107] Rainville, L. \& Pinkel, R. Propagation of low-mode internal waves through the ocean. J. Phys. Oceanogr. 36, $1220-1236(2006)$.

[108] Polzin, K. L. Mesoscale Eddy-Internal Wave Coupling. Part I: Symmetry, Wave Capture, and Results from the Mid-Ocean Dynamics Experiment. J. Phys. Oceanogr. 38, 2556-2574 (2008).

[109] Polzin, K. L. Mesoscale Eddy-Internal Wave Coupling. Part II: Energetics and Results from PolyMode. J. Phys. Oceanogr. 40, 789-801 (2010).

[110] Kelly, S. M., Lermusiaux, P. F., Duda, T. F. \& Haley Jr, P. J. A coupled-mode shallow-water model for tidal analysis: internal tide reflection and refraction by the Gulf Stream. J. Phys. Oceanogr. 46, 3661-3679 (2016). 
[111] Buijsman, M. C. et al. Semidiurnal internal tide incoherence in the equatorial Pacific. J. Geophys. Res. Oceans: Oceans 122, 5286-5305 (2017).

[112] Dunphy, M., Ponte, A. L., Klein, P. \& Le Gentil, S. Low-mode internal tide propagation in a turbulent eddy field. J. Phys. Oceanogr. 47, 649-665 (2017).

[113] Pollard, R. T. \& Millard, R. C. Comparison between observed and simulated wind-generated inertial oscillations. In Deep Sea Research and Oceanographic Abstracts, vol. 17, 813-821 (Elsevier, 1970).

[114] Alford, M. H. \& Whitmont, M. Seasonal and spatial variability of near-inertial kinetic energy from historical moored velocity records. J. Phys. Oceanogr. 37, 2022-2037 (2007).

[115] Whalen, C. B., MacKinnon, J. A. \& Talley, L. D. Large-scale impacts of the mesoscale environment on mixing from wind-driven internal waves. Nature Geosci. 11, 842-847 (2018).

[116] D'Asaro, E. A. et al. Upper-ocean inertial currents forced by a strong storm. I: Data and comparisons with linear-theory. J. Phys. Oceanogr. 25, 2909-2936 (1995).

[117] Price, J. F. Internal wave wake of a moving storm. Part I. Scales, energy budget and observations. J. Phys. Oceanogr. 13, 949-965 (1983).

[118] Church, J. A., Joyce, T. \& Price, J. F. Current and density observations across the wake of Hurricane Gay. J. Phys. Oceanogr. 19, 259-265 (1989).

[119] Sanford, T. B., Price, J. F. \& Girton, J. B. Upper-ocean response to hurricane frances (2004) observed by profiling EM-APEX floats. J. Phys. Oceanogr. 41, 1041-1056 (2011).

[120] Dohan, K. \& Davis, R. E. Mixing in the transition layer during two storm events. J. Phys. Oceanogr. 41, 42-66 (2011).

[121] Johnston, T. S. et al. Decay mechanisms of near-inertial mixed layer oscillations in the Bay of Bengal. Oceanogr. 29, 180-191 (2016).

[122] Gill, A. E. On the behavior of internal waves in the wakes of storms. J. Phys. Oceanogr. 14, 1129-1151 (1984).

[123] Alford, M. H. Redistribution of energy available for ocean mixing by long-range propagation of internal waves. Nature 423, 159-162 (2003).

[124] Alford, M., Cronin, M. \& Klymak, J. Annual cycle and depth penetration of wind-generated near-inertial internal waves at Ocean Station Papa in the Northeast Pacific. J. Phys. Oceanogr. 42, 889-909 (2012).

[125] Chaigneau, A., Pizarro, O. \& Rojas, W. Global climatology of near-inertial current characteristics from Lagrangian observations. Geophys. Res. Lett. 35 (2008). 
[126] Furuichi, N., Hibiya, T. \& Niwa, Y. Model-predicted distribution of wind-induced internal wave energy in the world's oceans. J. Geophys. Res. Oceans: Oceans 113 (2008).

[127] Zhai, X., Greatbatch, R. J., Eden, C. \& Hibiya, T. On the loss of wind-induced near-inertial energy to turbulent mixing in the upper ocean. J. Phys. Oceanogr. 39, 3040-3045 (2009).

[128] Rimac, A., Storch, J.-S. v. \& Eden, C. The total energy flux leaving the ocean's mixed layer. J. Phys. Oceanogr. 46, 1885-1900 (2016).

[129] Jouanno, J., Capet, X., Madec, G., Roullet, G. \& Klein, P. Dissipation of the energy imparted by mid-latitude storms in the Southern Ocean. Ocean Sci. 12, 743-769 (2016).

[130] Weller, R. A. The relation of near-inertial motions observed in the mixed layer during the JASIN (1978) experiment to the local wind stress and to the quasi-geostrophic flow field. J. Phys. Oceanogr. 12, 1122-1136 (1982).

[131] Jing, Z., Wu, L. \& Ma, X. Energy Exchange between the Mesoscale Oceanic Eddies and Wind-Forced NearInertial Oscillations. J. Phys. Oceanogr. 47, 721-733 (2017).

[132] Whitt, D. B. \& Thomas, L. N. Resonant generation and energetics of wind-forced near-inertial motions in a geostrophic flow. J. Phys. Oceanogr. 45, 181-208 (2015).

[133] Van Meurs, P. Interactions between near-inertial mixed layer currents and the mesoscale: The importance of spatial variabilities in the vorticity field. J. Phys. Oceanogr. 28, 1363-1388 (1998).

[134] D'Asaro, E. A. Upper-ocean inertial currents forced by a strong storm. Part iii: Interaction of inertial currents and mesoscale eddies. J. Phys. Oceanogr. 25, 2953-2958 (1995).

[135] Elipot, S., Lumpkin, R. \& Prieto, G. Modification of inertial oscillations by the mesoscale eddy field. J. Geophys. Res.-Oceans 115 (2010).

[136] Simmons, H. L. \& Alford, M. H. Simulating the long-range swell of internal waves generated by ocean storms. Oceanogr. 25, 30-41 (2012).

[137] Rimac, A., Storch, J.-S., Eden, C. \& Haak, H. The influence of high-resolution wind stress field on the power input to near-inertial motions in the ocean. Geophys. Res. Lett. 40, 4882-4886 (2013).

[138] Alford, M. H. \& Gregg, M. C. Near-inertial mixing: Modulation of shear, strain and microstructure at low latitude. J. Geophys. Res.-Oceans 106, 16947-16968 (2001).

[139] Watanabe, M. \& Hibiya, T. Global estimates of the wind-induced energy flux to inertial motions in the surface mixed layer. Geophys. Res. Lett. 29, 64-1 (2002). 
[140] Plueddemann, A. \& Farrar, J. Observations and models of the energy flux from the wind to mixed-layer inertial currents. Deep-Sea Res. II 53, 5-30 (2006).

[141] Liu, G., Perrie, W. \& Hughes, C. Surface wave effects on the wind-power input to mixed layer near-inertial motions. J. Phys. Oceanogr. 47, 1077-1093 (2017).

[142] Jiang, J., Lu, Y. \& Perrie, W. Estimating the energy flux from the wind to ocean inertial motions: The sensitivity to surface wind fields. Geophys. Res. Lett. 32 (2005).

[143] Alford, M. H. Improved global maps and 54-year history of wind-work on ocean inertial motions. Geophys. Res. Lett. 30 (2003).

[144] Liu, Y., Jing, Z. \& Wu, L. Wind power on oceanic near-inertial oscillations in the global ocean estimated from surface drifters. Geophys. Res. Lett. 46, 2647-2653 (2019).

[145] Alford, M. H., MacKinnon, J. A., Pinkel, R. \& Klymak, J. M. Space-time scales of shear in the North Pacific. J. Phys. Oceanogr. 47, 2455-2478 (2017).

[146] Cuypers, Y., Le Vaillant, X., Bouruet-Aubertot, P., Vialard, J. \& Mcphaden, M. J. Tropical storm-induced near-inertial internal waves during the Cirene experiment: Energy fluxes and impact on vertical mixing. $J$. Geophys. Res. Oceans: Oceans 118, 358-380 (2013).

[147] Garrett, C. What is the "near-inertial" band and why is it different from the rest of the internal wave spectrum? J. Phys. Oceanogr. 31, 962-971 (2001).

[148] Jeon, C. et al. Poleward-propagating near-inertial waves enabled by the western boundary current. Scientific reports 9 (2019).

[149] Nagasawa, M., Niwa, Y. \& Hibiya, T. Spatial and temporal distribution of the wind-induced internal wave energy available for deep water mixing in the North Pacific. J. Geophys. Res. Oceans: Oceans 105, 1393313943 (2000).

[150] Komori, N., Ohfuchi, W., Taguchi, B., Sasaki, H. \& Klein, P. Deep ocean inertia-gravity waves simulated in a high-resolution global coupled atmosphere-ocean GCM. Geophys. Res. Lett. 35 (2008).

[151] Silverthorne, K. E. \& Toole, J. M. Seasonal kinetic energy variability of near-inertial motions. J. Phys. Oceanogr. 39, 1035-1049 (2009).

[152] Inoue, R., Watanabe, M. \& Osafune, S. Wind-induced mixing in the North Pacific. J. Phys. Oceanogr. 47, $1587-1603$ (2017).

[153] Kunze, E. Near-inertial wave-propagation in geostrophic shear. J. Phys. Oceanogr. 15, 544-565 (1985). 
[154] Young, W. \& Jelloul, M. B. Propagation of near-inertial oscillations through a geostrophic flow. J. Mar. Res. 55, 735-766 (1997).

[155] Klein, P., Smith, S. L. \& Lapeyre, G. Organization of near-inertial energy by an eddy field. Q. J. Roy. Meteor. Soc. 130, 1153-1166 (2004).

[156] Danioux, E., Klein, P. \& Rivière, P. Propagation of wind energy into the deep ocean through a fully turbulent mesoscale eddy field. J. Phys. Oceanogr. 38, 2224-2241 (2008).

[157] Mooers, C. N. Several effects of a baroclinic current on the cross-stream propagation of inertial-internal waves. Geophys. Astro. Fluid. 6, 245-275 (1975).

[158] Whitt, D. \& Thomas, L. Near-inertial waves in strongly baroclinic currents. J. Phys. Oceanogr. $706-725$ (2013).

[159] Whitt, D. B., Thomas, L. N., Klymak, J. M., Lee, C. M. \& D'Asaro, E. A. Interaction of superinertial waves with submesoscale cyclonic filaments in the north wall of the Gulf Stream. J. Phys. Oceanogr. 48, 81-99 (2018).

[160] Padman, L., Levine, M., Dillon, T., Morison, J. \& Pinkel, R. Hydrography and microstructure of an Arctic Cyclonic Eddy. J. Geophys. Res.-Oceans 95, 9411-9420 (1990).

[161] Kunze, E. The energy-balance in a warm-core rings near-inertial critical layer. J. Phys. Oceanogr. 25, 942-957 (1995).

[162] Joyce, T., Toole, J., Klein, P. \& Thomas, L. A Near-Inertial Mode observed within a Gulf Stream Warm-Core Ring. J. Geophys. Res. (2013).

[163] Sheen, K. et al. Modification of turbulent dissipation rates by a deep Southern Ocean eddy. Geophys. Res. Lett. (2015).

[164] Fer, I., Bosse, A., Ferron, B. \& Bouruet-Aubertot, P. The dissipation of kinetic energy in the Lofoten Basin Eddy. J. Phys. Oceanogr. 48, 1299-1316 (2018).

[165] Wunsch, C. The work done by the wind on the oceanic general circulation. J. Phys. Oceanogr. 28, 2332-2340 (1998).

[166] von Storch, J.-S., Sasaki, H. \& Marotzke, J. Wind-generated power input to the deep ocean: An estimate using a 1/10 general circulation model. J. Phys. Oceanogr. 37, 657-672 (2007).

[167] Arbic, B. K. \& Flierl, G. R. Baroclinically unstable geostrophic turbulence in the limits of strong and weak bottom Ekman friction: Application to midocean eddies. J. Phys. Oceanogr. 34, 2257-2273 (2004).

[168] Sen, A., Scott, R. B. \& Arbic, B. K. Global energy dissipation rate of deep-ocean low-frequency flows by quadratic bottom boundary layer drag: Computations from current-meter data. Geophys. Res. Lett. 35 (2008). 
[169] Klymak, J. M. Nonpropagating form drag and turbulence due to stratified flow over large-scale abyssal hill topography. J. Phys. Oceanogr. 48, 2383-2395 (2018).

[170] Renault, L. et al. Modulation of wind work by oceanic current interaction with the atmosphere. J. Phys. Oceanogr. 46, 1685-1704 (2016).

[171] Nikurashin, M. \& Ferrari, R. Global energy conversion rate from geostrophic flows into internal lee waves in the deep ocean. Geophys. Res. Lett. 38 (2011).

[172] Scott, R. B., Goff, J. A., Naveira Garabato, A. \& Nurser, A. Global rate and spectral characteristics of internal gravity wave generation by geostrophic flow over topography. J. Geophys. Res. Oceans: Oceans 116 (2011).

[173] Wright, C. J., Scott, R. B., Ailliot, P. \& Furnival, D. Lee wave generation rates in the deep ocean. Geophys. Res. Lett. 41, 2434-2440 (2014).

[174] Nikurashin, M., Ferrari, R., Grisouard, N. \& Polzin, K. The impact of finite-amplitude bottom topography on internal wave generation in the Southern Ocean. J. Phys. Oceanogr. 44, 2938-2950 (2014).

[175] Yang, L., Nikurashin, M., Hogg, A. M. \& Sloyan, B. M. Energy loss from transient eddies due to lee wave generation in the Southern Ocean. J. Phys. Oceanogr. 48, 2867-2885 (2018).

[176] Melet, A., Hallberg, R., Adcroft, A., Nikurashin, M. \& Legg, S. Energy flux into internal lee waves: sensitivity to future climate changes using linear theory and a climate model. J. Clim. 28, 2365-2384 (2015).

[177] Zheng, K. \& Nikurashin, M. Downstream propagation and remote dissipation of internal waves in the southern ocean. J. Phys. Oceanogr. 49, 1873-1887 (2019).

[178] Waterman, S., Garabato, A. C. N. \& Polzin, K. L. Internal Waves and Turbulence in the Antarctic Circumpolar Current. J. Phys. Oceanogr. 43, 259-282 (2013).

[179] Sheen, K. L. et al. Rates and mechanisms of turbulent dissipation and mixing in the Southern Ocean: Results from the Diapycnal and Isopycnal Mixing Experiment in the Southern Ocean (DIMES). J. Geophys. Res.: Oceans 118, 2774-2792 (2013).

[180] Meyer, A., Sloyan, B. M., Polzin, K. L., Phillips, H. E. \& Bindoff, N. L. Mixing variability in the Southern Ocean. J. Phys. Oceanogr. 45, 966-987 (2015).

[181] Cusack, J. M., Naveira Garabato, A. C., Smeed, D. A. \& Girton, J. B. Observation of a large lee wave in the Drake Passage. J. Phys. Oceanogr. 47, 793-810 (2017).

[182] Clement, L., Frajka-Williams, E., Sheen, K., Brearley, J. \& Garabato, A. N. Generation of internal waves by eddies impinging on the western boundary of the North Atlantic. J. Phys. Oceanogr. 46, 1067-1079 (2016). 
[183] Brearley, J. A., Sheen, K. L., Naveira Garabato, A. C., Smeed, D. A. \& Waterman, S. Eddy-induced modulation of turbulent dissipation over rough topography in the Southern Ocean. J. Phys. Oceanogr. 43, 2288-2308 (2013).

[184] Köhler, J. et al. Variability in the internal wave field induced by the Atlantic Deep Western Boundary Current at 16 N. J. Phys. Oceanogr. 44, 492-516 (2014).

[185] Sheen, K. et al. Eddy-induced variability in Southern Ocean abyssal mixing on climatic timescales. Nature Geosci. 7, 577?582 (2014).

[186] Kunze, E. \& Lien, R.-C. Energy sinks for lee waves in shear flow. J. Phys. Oceanogr. (2019).

[187] Naveira Garabato, A. C., Polzin, K. L., King, B. A., Heywood, K. J. \& Visbeck, M. Widespread intense turbulent mixing in the Southern Ocean. Science 303, 210-213 (2004).

[188] St. Laurent, L. et al. Turbulence and diapycnal mixing in Drake Passage. J. Phys. Oceanogr. 42, $2143-2152$ (2012).

[189] Alford, M. H. et al. Turbulent mixing and hydraulic control of abyssal water in the Samoan Passage. Geophys. Res. Lett. 40, 4668-4674 (2013).

[190] Thurnherr, A. Diapycnal mixing associated with an overflow in a deep submarine canyon. Deep-Sea Res. Oceanogr. Abstr. 53, 194-206 (2006).

[191] Nikurashin, M. \& Ferrari, R. Radiation and dissipation of internal waves generated by geostrophic motions impinging on small-scale topography: Theory. J. Phys. Oceanogr. 40, 1055-1074 (2010).

[192] Trossman, D. S. et al. Internal lee wave closures: Parameter sensitivity and comparison to observations. J. Geophys. Res. Oceans: Oceans 120, 7997-8019 (2015).

[193] Griffiths, M. \& Reeder, M. J. Stratospheric inertia-gravity waves generated in a numerical model of frontogenesis. I: Model solutions. Q. J. Roy. Meteor. Soc. 122, 1153-1174 (1996).

[194] Reeder, M. J. \& Griffiths, M. Stratospheric inertia-gravity waves generated in a numerical model of frontogenesis. II: Wave sources, generation mechanisms and momentum fluxes. Q. J. Roy. Meteor. Soc. 122, 1175-1195 (1996).

[195] Danioux, E., Vanneste, J., Klein, P. \& Sasaki, H. Spontaneous inertia-gravity-wave generation by surfaceintensified turbulence. J. Fluid Mech. 699, 153-173 (2012).

[196] Vanneste, J. Balance and spontaneous wave generation in geophysical flows. Ann. Rev. Fluid Mech. (2013).

[197] Snyder, C., Skamarock, W. C. \& Rotunno, R. Frontal dynamics near and following frontal collapse. J. Atmos. Sci. 50, 3194-3212 (1993). 
[198] Nagai, T., Tandon, A., Kunze, E. \& Mahadevan, A. Spontaneous generation of near-inertial waves by the Kuroshio Front. J. Phys. Oceanogr. 45, 2381-2406 (2015).

[199] Shakespeare, C. J. \& Hogg, A. M. Spontaneous surface generation and interior amplification of internal waves in a regional-scale ocean model. J. Phys. Oceanogr. 47, 811-826 (2017).

[200] Rossby, C. On the mutual adjustment of pressure and velocity distributions in certain simple current systems. J. Mar. Res 1, 280 (1937).

[201] Ford, R. Gravity wave radiation from vortex trains in rotating shallow water. J. Fluid Mech. 281, 81-118 (1994).

[202] Xie, J.-H. \& Vanneste, J. A generalised-Lagrangian-mean model of the interactions between near-inertial waves and mean flow. J. Fluid Mech. 774, 143-169 (2015).

[203] Wagner, G. \& Young, W. A three-component model for the coupled evolution of near-inertial waves, quasigeostrophic flow and the near-inertial second harmonic. J. Fluid Mech. 802, 806-837 (2016).

[204] Thomas, L. N. On the effects of frontogenetic strain on symmetric instability and inertia-gravity waves. J. Fluid Mech. 711, 620-640 (2012).

[205] Alford, M. H., Shcherbina, A. Y. \& Gregg, M. C. Observations of near-inertial internal gravity waves radiating from a frontal jet. J. Phys. Oceanogr. 43, 1225-1239 (2013).

[206] Ferrari, R. \& Wunsch, C. The distribution of eddy kinetic and potential energies in the global ocean. Tellus Series a-Dynamic Meteorology and Oceanography 62, 92-108 (2010).

[207] Shakespeare, C. J. \& Hogg, A. The life cycle of spontaneously generated internal waves. J. Phys. Oceanogr. 48, $343-359$ (2018).

[208] Toggweiler, J. \& Samuels, B. On the ocean's large-scale circulation near the limit of no vertical mixing. J. Phys. Oceanogr. 28, 1832-1852 (1998).

[209] Oka, A. \& Niwa, Y. Pacific deep circulation and ventilation controlled by tidal mixing away from the sea bottom. Nat. Commun. 4, 2419 (2013).

[210] Melet, A., Legg, S. \& Hallberg, R. Climatic impacts of parameterized local and remote tidal mixing. J. Clim. 29, 3473-3500 (2016).

[211] Hieronymus, M., Nycander, J., Nilsson, J., Döös, K. \& Hallberg, R. Oceanic overturning and heat transport: The role of background diffusivity. J. Clim. 32, 701-716 (2019). 
[212] Adcroft, A., Scott, J. R. \& Marotzke, J. Impact of geothermal heating on the global ocean circulation. Geophys. Res. Lett. 28, 1735-1738 (2001).

[213] Emile-Geay, J. \& Madec, G. Geothermal heating, diapycnal mixing and the abyssal circulation. Ocean Science 5, 203-217 (2009).

[214] Naveira Garabato, A. C. et al. Rapid mixing and exchange of deep-ocean waters in an abyssal boundary current. Proc. Natl. Acad. Sci. U.S.A. (2019).

[215] Bryden, H. L. \& Nurser, A. G. Effects of strait mixing on ocean stratification. J. Phys. Oceanogr. 33, 1870-1872 (2003).

[216] Ganachaud, A. Large-scale mass transports, water mass formation, and diffusivities estimated from World Ocean Circulation Experiment (WOCE) hydrographic data. J. Geophys. Res. Oceans: Oceans 108 (2003).

[217] Lumpkin, R. \& Speer, K. Global ocean meridional overturning. J. Phys. Oceanogr. 37, 2550-2562 (2007).

[218] Jayne, S. R. The impact of abyssal mixing parameterizations in an ocean general circulation model. J. Phys. Oceanogr. 39, 1756-1775 (2009).

[219] De Lavergne, C., Madec, G., Le Sommer, J., Nurser, A. G. \& Naveira Garabato, A. C. The impact of a variable mixing efficiency on the abyssal overturning. J. Phys. Oceanogr. 46, 663-681 (2016).

[220] Melet, A., Hallberg, R., Legg, S. \& Nikurashin, M. Sensitivity of the ocean state to lee wave-driven mixing. J. Phys. Oceanogr. 44, 900-921 (2014).

[221] Saenko, O. \& Merryfield, W. On the effect of topographically enhanced mixing on the global ocean circulation. J. Phys. Oceanogr. 35, 826-834 (2005).

[222] Simmons, H. L., Jayne, S. R., Laurent, L. C. S. \& Weaver, A. J. Tidally driven mixing in a numerical model of the ocean general circulation. Ocean Modelling 6, 245-263 (2004).

[223] Melet, A., Hallberg, R., Legg, S. \& Polzin, K. Sensitivity of the ocean state to the vertical distribution of internal-tide-driven mixing. J. Phys. Oceanogr. 43, 602-615 (2013).

[224] Tatebe, H., Tanaka, Y., Komuro, Y. \& Hasumi, H. Impact of deep ocean mixing on the climatic mean state in the Southern Ocean. Scientific reports 8, 14479 (2018).

[225] Zhu, Y. \& Zhang, R.-H. A modified vertical mixing parameterization for its improved ocean and coupled simulations in the tropical Pacific. J. Phys. Oceanogr. 49, 21-37 (2019).

[226] Jochum, M. et al. The impact of oceanic near-inertial waves on climate. J. Clim. 26, 2833-2844 (2013). 
[227] Stanley, G. J. \& Saenko, O. A. Bottom-enhanced diapycnal mixing driven by mesoscale eddies: Sensitivity to wind energy supply. J. Phys. Oceanogr. 44, 68-85 (2014).

[228] Koch-Larrouy, A., Lengaigne, M., Terray, P., Madec, G. \& Masson, S. Tidal mixing in the indonesian seas and its effect on the tropical climate system. Climate Dynamics 34, 891-904 (2010).

[229] Kida, S. \& Wijffels, S. The impact of the Indonesian Throughflow and tidal mixing on the summertime sea surface temperature in the western indonesian seas. J. Geophys. Res. Oceans: Oceans 117 (2012).

[230] Sasaki, H., Kida, S., Furue, R., Nonaka, M. \& Masumoto, Y. An increase of the Indonesian Throughflow by internal tidal mixing in a high-resolution quasi-global ocean simulation. Geophys. Res. Lett. 45, 8416-8424 (2018).

[231] Saenko, O. A., Zhai, X., Merryfield, W. J. \& Lee, W. G. The combined effect of tidally and eddy-driven diapycnal mixing on the large-scale ocean circulation. J. Phys. Oceanogr. 42, 526-538 (2012).

[232] Munday, D., Allison, L., Johnson, H. \& Marshall, D. Remote forcing of the Antarctic Circumpolar Current by diapycnal mixing. Geophys. Res. Lett. 38 (2011).

[233] Savva, M. A. \& Vanneste, J. Scattering of internal tides by barotropic quasigeostrophic flows. J. Fluid Mech. 856, 504-530 (2018).

[234] Zaron, E. D. Topographic and frictional controls on tides in the sea of okhotsk. Ocean Modelling 117, 1-11 (2017).

[235] Alford, M. H., Simmons, H. L., Marques, O. B. \& Girton, J. B. Internal tide attenuation in the North Pacific. Geophys. Res. Lett. 46, 8205-8213 (2019).

[236] Naveira Garabato, A. C., Nurser, A. G., Scott, R. B. \& Goff, J. A. The impact of small-scale topography on the dynamical balance of the ocean. J. Phys. Oceanogr. 43, 647-668 (2013).

[237] Klymak, J. M., Pinkel, R. \& Rainville, L. Direct breaking of the internal tide near topography: Kaena ridge, Hawaii. J. Phys. Oceanogr. 38, 380-399 (2008).

[238] Zhao, Z. et al. Decomposition of the multimodal multidirectional M2 internal tide field. J. Atmos. Ocean. Technol. 36, 1157-1173 (2019). 


\section{Internal Wave Driven Mixing}

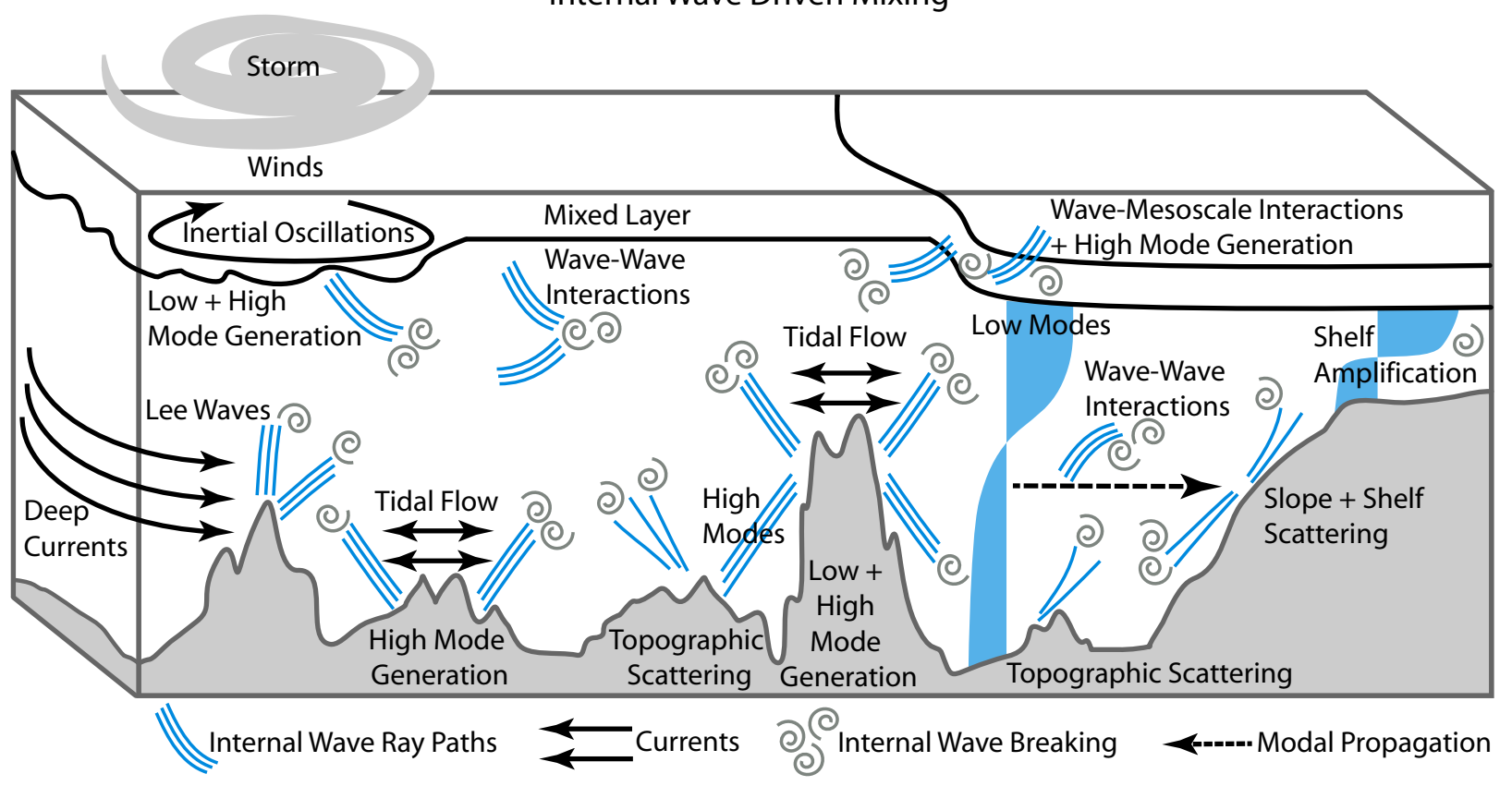

FiguRE 1. The primary internal wave mechanisms leading to ocean mixing.

Tides flow over many forms of topography, from abyssal hills to tall steep ridges, generat-

ing both high-mode and low-mode internal waves. Time-varying winds cause near-inertial oscillations in the mixed layer, radiating high- and low-mode internal waves. Lee waves are generated when deep currents impinge on topographic features. Time-varying surface currents can also generate internal waves. Both high and low modes propagate, undergo wave-wave interactions, and scatter off topographic features, eventually leading to dissipation. Low modes generated in the open ocean can also propagate and dissipate on continental slopes and shelves. Modified from Ref [21]. 

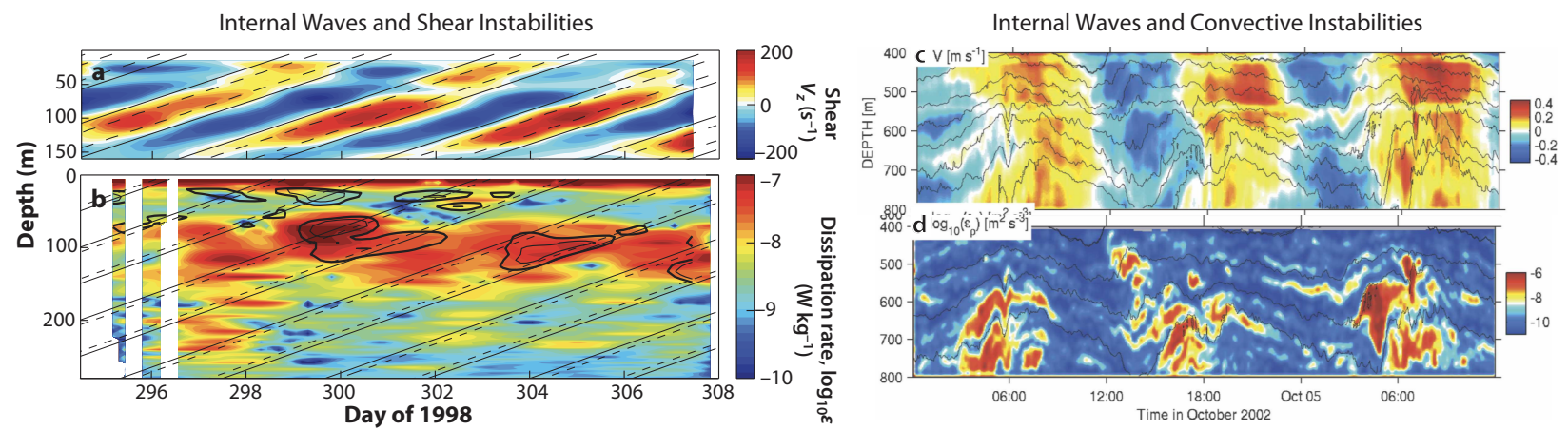

FiguRE 2. Turbulent mixing in two different internal wave environments. Merid-

ional component of vertical shear (a) and dissipation rate (b) in the presence of a near-inertial internal wave from Ref [138]. Elevated dissipation rates are associated with strong vertical shear in the internal wave field, and turbulent mixing is attributed to shear instabilities. Adapted from Meridional velocity (c) and dissipation rate (d) during tidal flow over the Hawaiian ridge from Ref [237]. Peaks in the dissipation rate are in phase with the tidal cycle and are indicative of convective instabilities. 


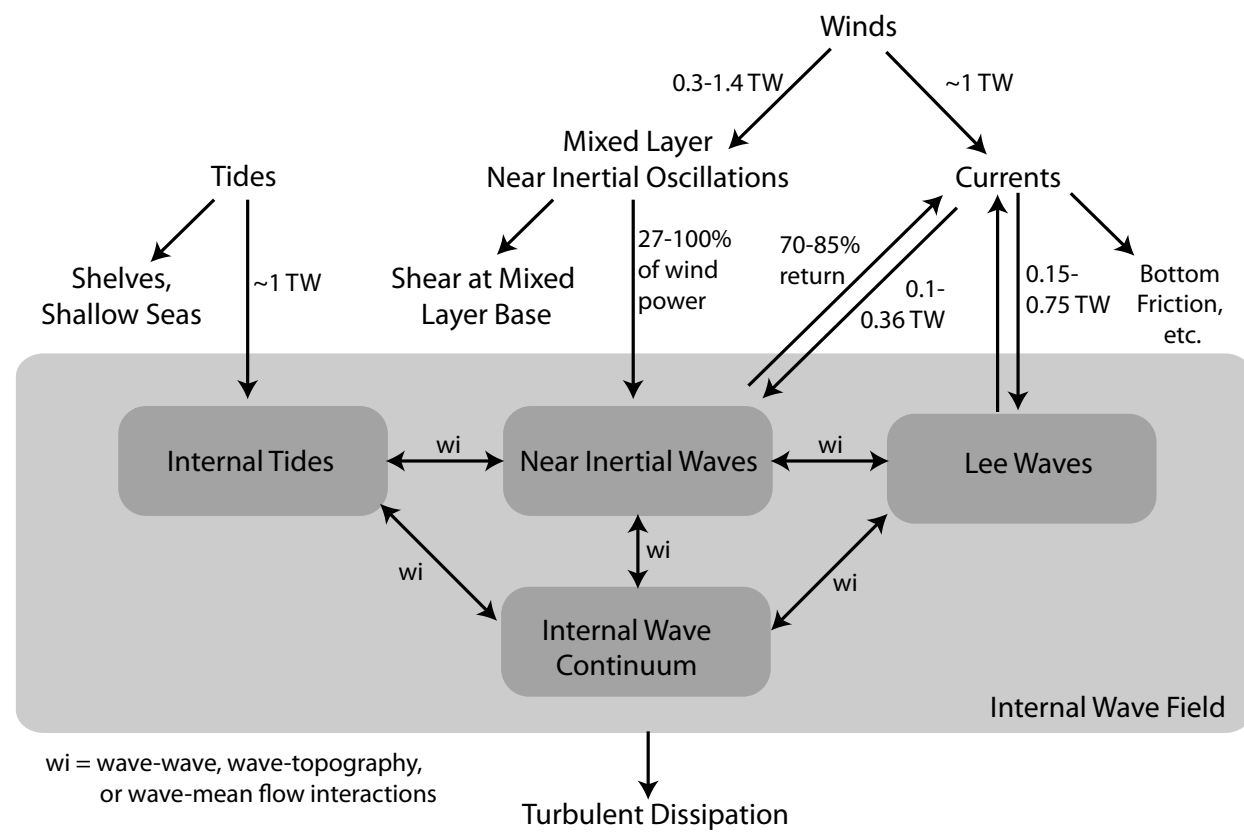

FigURE 3. A simplified global energy budget of internal waves. Included are the sources of internal wave energy and the pathways of energy transfer until it is dissipated through turbulence. References for numbers quantifying energy transfers are provided in the main text. 
(a) Internal Tide Energy Disispation $\left[\log _{10}\left(\mathrm{~W} \mathrm{~m}^{-2}\right)\right]$
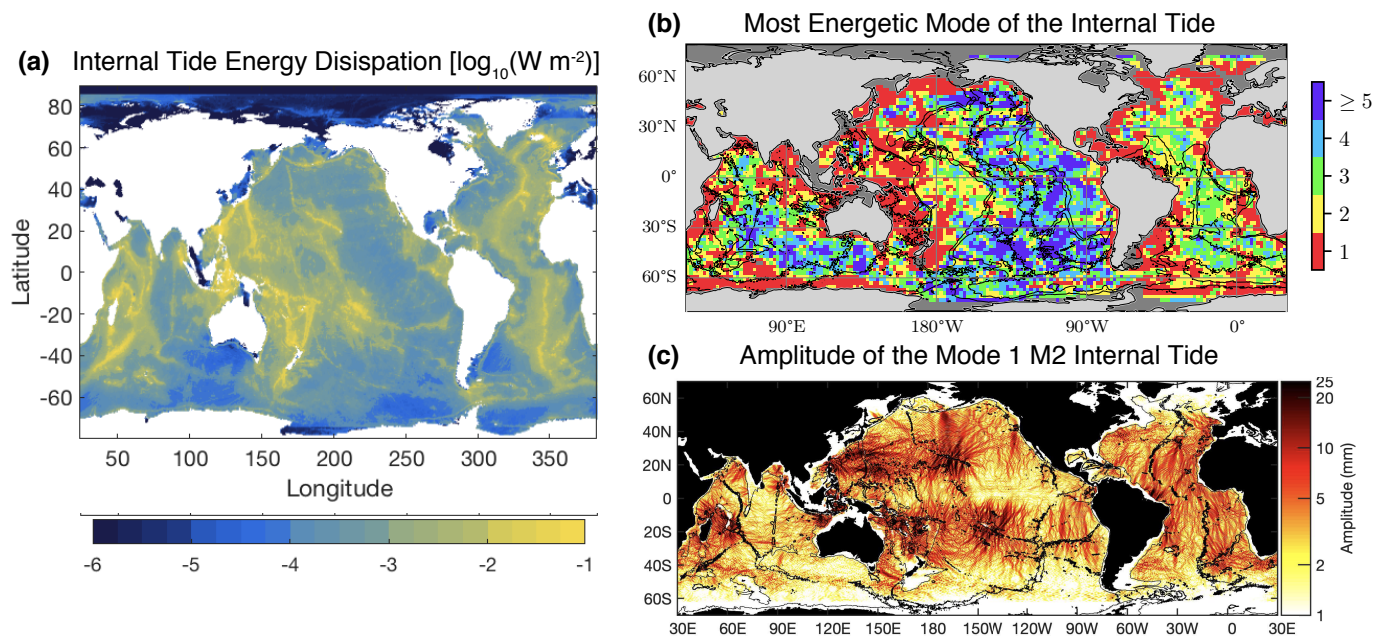

FIgURE 4. The lifecycle of internal tides, including generation, propagation, and turbulent dissipation. (a) A global map of the dissipation of the internal tide from a modelling study modified from Ref [63], (b) The most energetic mode (that is, vertical length scale) of internal tide generation varies throughout the globe, depending primarily on the geometry of the seafloor from Ref [68]. (c) The propagation of the first mode (the largest vertical length scale) $M_{2}$ internal tide can be tracked using sea surface height from altimetry up to thousands of kilometers away from the steep topographic generation sites [70] using an updated model [238] as explained in Ref [86]. 

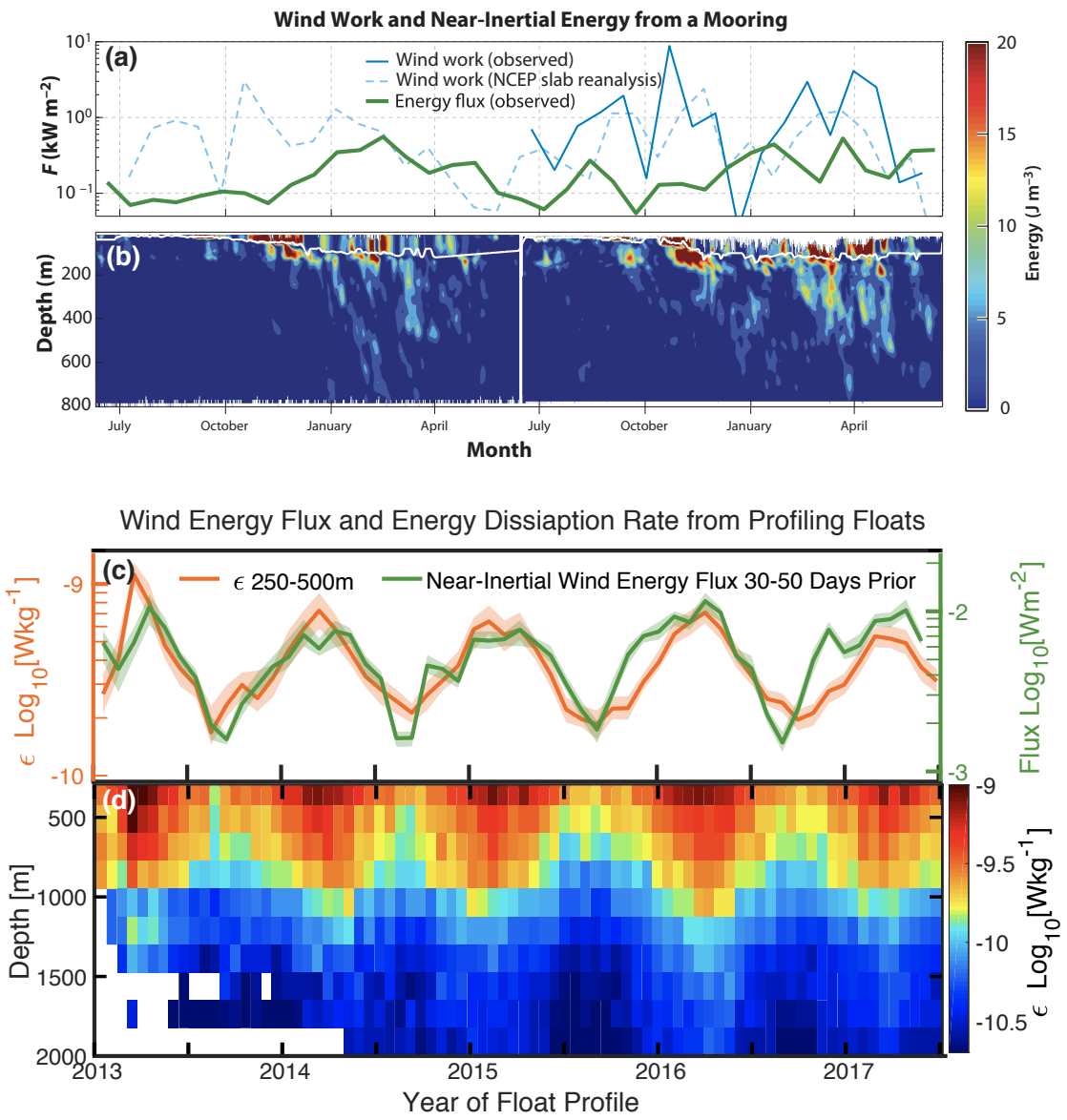

FIGURE 5. The seasonal cycle in wind activity tracks the seasonal cycle in near-

inertial wave energy and dissipation rate in the North Pacific. (a-b) Mooring data show that the wind energy input into the mixed layer is elevated in the winter months, followed by an invigoration of the near-inertial internal wave field in the thermocline below, suggesting that the mixed layer oscillations radiate near-inertial internal waves (Modified from Ref[124]). A fraction of these waves will undergo turbulent dissipation locally. In fact, (c-d) the energy dissipation rate estimated using profiling float data also peaks in the winter, (c) lagging the wind energy flux from Ref [115]. 

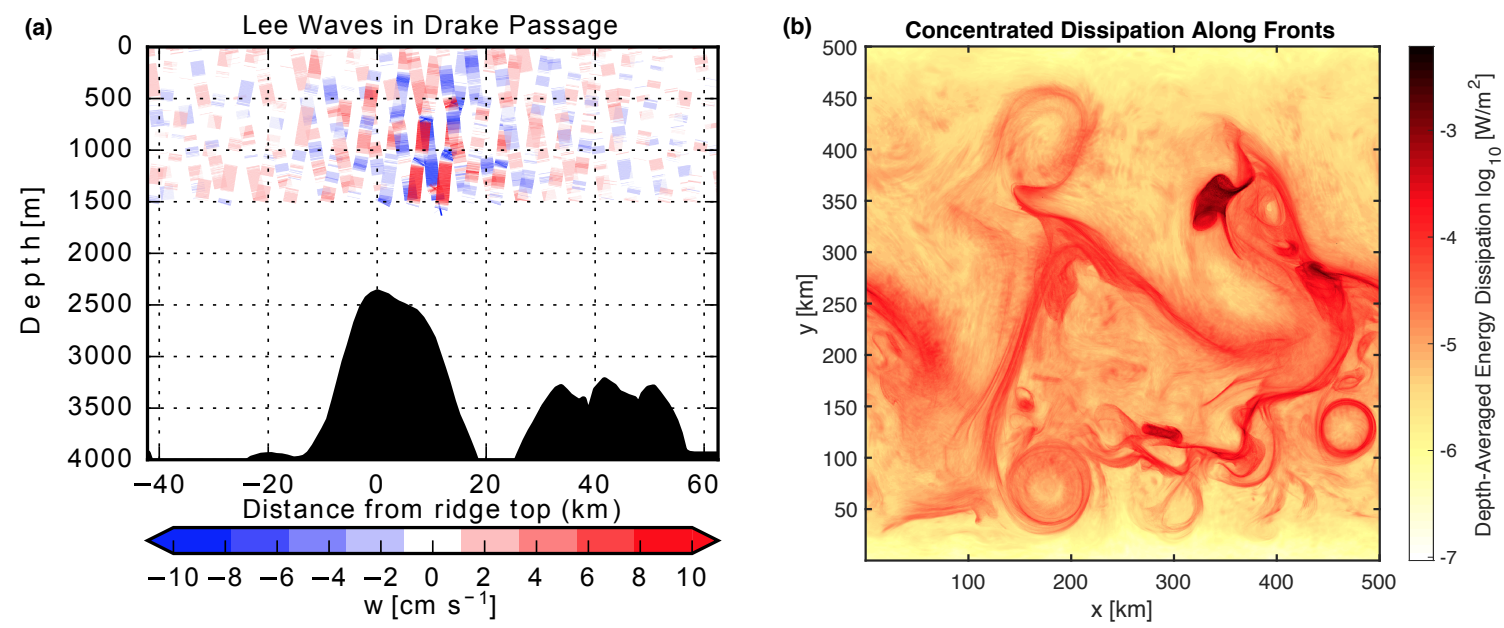

FigURE 6. Two mechanisms for internal wave generation from geographic cur-

rent. (a) Vertical velocity associated with lee waves in Drake Passage observed using profiling floats. (b) The vertically integrated energy dissipation in a high-resolution ocean model. Internal waves generated at fronts preferentially dissipate along those fronts. (a) Is from Ref [181] and (b) is modified from Ref [207]. 


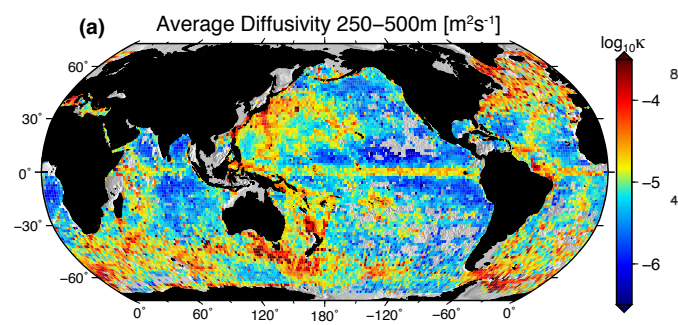

(c) Air-Sea Heat Flux, Sea Ice Extent, and Ocean Temperature Changes
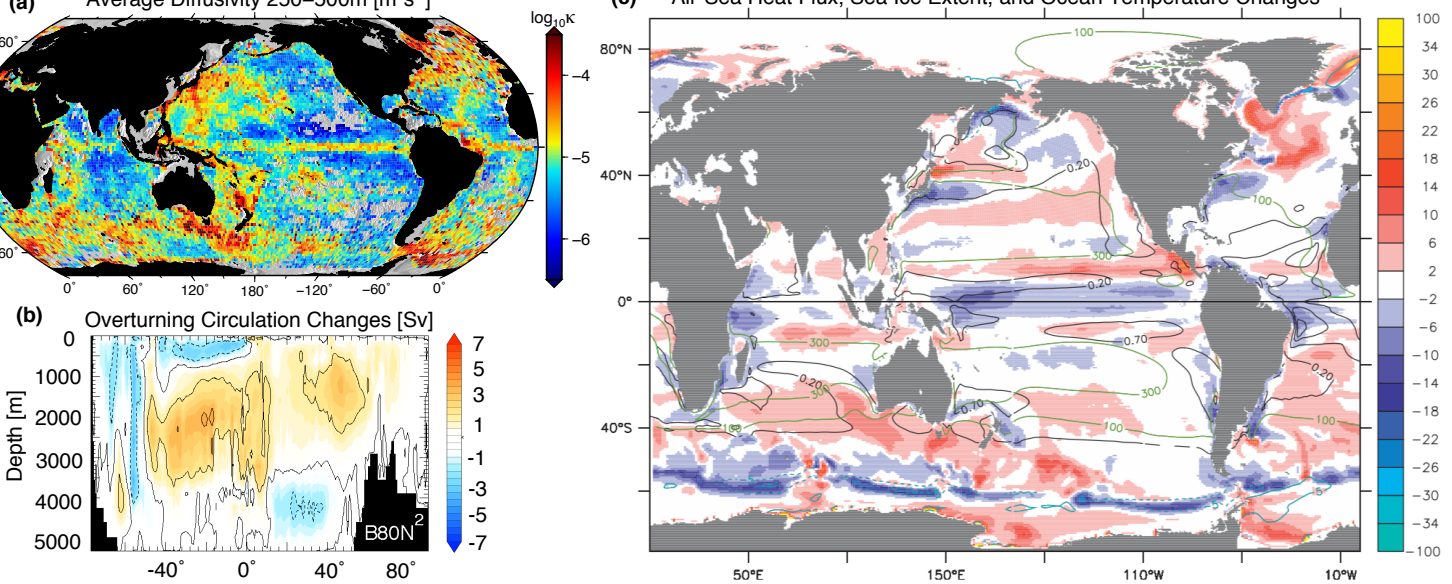

FigURE 7. Global diapycnal mixing from internal waves and implications for

circulation and climate. (a) The diffusivity estimated from profiling floats averaged between 250-500 m exhibits large geographic variability throughout the ocean (modified from Ref [115]). (b) The overturning circulation changes significantly when far-field tidal mixing is assigned to the basins compared to distributed across the basins, continental slopes and shelves (modified from Ref [210]). (c) Adding diffusivity from wind-generated near-inertial waves changes the downward surface heat flux (colors), sea ice extent (blue lines) and temperature on the $26 \mathrm{~kg} \mathrm{~m}^{-3}$ density surface (black line). The depth of $26 \mathrm{~kg}$ $\mathrm{m}^{-3}$ density surface is contoured in green, modified from Ref [226]. 